\title{
Thermoacoustic Instability Considerations for High Hydrogen Combustion in Lean Premixed Gas Turbine Combustors: A Review
}

\author{
Jadeed Beita ${ }^{1,2, *}$, Midhat Talibi ${ }^{2}$ (D), Suresh Sadasivuni ${ }^{1}$ and Ramanarayanan Balachandran ${ }^{2, *(D)}$ \\ 1 Siemens Industrial Turbomachinery Ltd., 1, Waterside South, Lincoln LN5 7FD, UK; \\ suresh.sadasivuni@siemens-energy.com \\ 2 Department of Mechanical Engineering, University College London, London WC1E 7JE, UK; \\ m.talibi@ucl.ac.uk \\ * Correspondence: jadeed.beita@siemens-energy.com (J.B.); r.balachandran@ucl.ac.uk (R.B.)
}

Citation: Beita, J.; Talibi, M.;

Sadasivuni, S.; Balachandran, R.

Thermoacoustic Instability

Considerations for High Hydrogen Combustion in Lean Premixed Gas Turbine Combustors: A Review.

Hydrogen 2021, 2, 33-57. https:/ /

doi.org/10.3390/hydrogen2010003

Received: 30 October 2020

Accepted: 2 January 2021

Published: 8 January 2021

Publisher's Note: MDPI stays neutral with regard to jurisdictional clai$\mathrm{ms}$ in published maps and institutional affiliations.

Copyright: (C) 2021 by the authors. Licensee MDPI, Basel, Switzerland. This article is an open access article distributed under the terms and conditions of the Creative Commons Attribution (CC BY) license (https: / / creativecommons.org/licenses/by/ $4.0 /)$.

\begin{abstract}
Hydrogen is receiving increasing attention as a versatile energy vector to help accelerate the transition to a decarbonised energy future. Gas turbines will continue to play a critical role in providing grid stability and resilience in future low-carbon power systems; however, it is recognised that this role is contingent upon achieving increased thermal efficiencies and the ability to operate on carbon-neutral fuels such as hydrogen. An important consideration in the development of gas turbine combustors capable of operating with pure hydrogen or hydrogenenriched natural gas are the significant changes in thermoacoustic instability characteristics associated with burning these fuels. This article provides a review of the effects of burning hydrogen on combustion dynamics with focus on swirl-stabilised lean-premixed combustors. Experimental and numerical evidence suggests hydrogen can have either a stabilising or destabilising impact on the dynamic state of a combustor through its influence particularly on flame structure and flame position. Other operational considerations such as the effect of elevated pressure and piloting on combustion dynamics as well as recent developments in micromix burner technology for $100 \%$ hydrogen combustion have also been discussed. The insights provided in this review will aid the development of instability mitigation strategies for high hydrogen combustion.
\end{abstract}

Keywords: hydrogen; gas turbines; combustion; thermoacoustic instabilities; lean premixed; micromix

\section{Introduction}

\subsection{Hydrogen as a Clean Energy Vector}

It is widely recognised that significant decarbonisation of large parts of the world's energy systems will be required to achieve inclusive energy access while limiting global temperature rise this century to well below $2{ }^{\circ} \mathrm{C}$ above pre-industrial levels as set out in the UN Paris agreement of 2016 [1,2]. In recent years, hydrogen has received renewed interest as a clean and sustainable energy carrier to help deliver significant emissions reduction and is regarded as a powerful accelerator to achieve a low carbon future [3,4]. Hydrogen promotes sector coupling in global energy systems [5,6] and enables deep emissions reduction in sectors that are difficult to decarbonise through electrification $[4,7,8]$. Hydrogen facilitates the integration of increasing share of variable renewable energy technologies (RET) in the energy mix while enhancing the level of flexibility in the power system [3]. It has been recognised as the most promising solution for large-scale and long-term carbon-free seasonal energy storage $[9,10]$ and is expected to play a leading role in balancing the intermittent outputs of solar and wind energy [11]. Zero or low carbon hydrogen can be produced via water electrolysis using electricity from RET or other low carbon technologies and 
stored in what is known as power-to-gas [12]. The stored hydrogen can then be reconverted to electricity when required by burning in a gas turbine, for example, or used in a fuel cell system. Hydrogen therefore has an important role to play in reducing dependency on fossil fuels in the power sector and ensuring energy security.

\subsection{Towards $100 \%$ Hydrogen Combustion in Gas Turbines}

Gas turbines play a vital role in the power generation mix of today because of their high efficiencies, operational and fuel flexibility, high power density, low emissions characteristics and favourable economics [13]. Operating in combined-cycle configuration, they are the cleanest form of fossil fuel power generation [14]. Given the intermittency of RET, gas turbines are relied upon by grid operators to provide dispatchable power to balance instantaneous supply and demand [14]. Increasing shares of installed solar and wind power generation capacity $[1,15]$ means advanced gas turbines will be relied upon even more to meet the system flexibility and energy security needs of future power systems. However, the role of gas turbines in a low-carbon future is contingent upon higher plant efficiencies and carbon-neutrality facilitated through technological innovations in combined heat and power, large-scale carbon capture and storage as well as operation with carbon-neutral fuels like hydrogen [16-18].

Burning pure hydrogen or hydrogen-enriched natural gas leads to significant differences in combustion characteristics in comparison to pure natural gas. Gas turbines equipped with diffusion flame combustors can burn up to $100 \%$ hydrogen, albeit requiring expensive nitrogen oxides $\left(\mathrm{NO}_{\mathrm{x}}\right)$ emission abatement strategies which result in additional power plant complexities and efficiency penalties [19]. Those fitted with lean premixed (LPM) combustors, the current state-of-the-art for low $\mathrm{NO}_{\mathrm{x}}$ operation $[16,20,21]$, are generally limited to about $30 \%$ hydrogen by volume [14]. LPM combustors operate close to the lean blowout (LBO) with a high degree of fuelair premixing which makes them susceptible to thermoacoustic instabilities [22,23]. Also known as combustion instabilities or dynamic instabilities, these refer to damaging pressure oscillations which arise from coupled interaction between unsteady combustion processes and acoustic waves propagating in the combustor [23,24] and have generally hindered the development of LPM combustors [24,25]. Research efforts are ongoing to develop gas turbine combustion technologies which can operate with any blend of natural gas and hydrogen, including pure hydrogen, while still achieving low $\mathrm{NO}_{x}$ emissions commensurate with natural gas-fired engines $[14,18]$. However, operating LPM combustors with very high hydrogen concentrations or pure hydrogen is fraught with many technical challenges, one of which is the significant changes to the thermoacoustic instability characteristics of the combustor.

\subsection{Purpose and Scope of Review}

Motivated by the need to address the technical challenges of burning high hydrogen concentrations in LPM combustors, many researchers have carried out detailed experimental and numerical studies, at laboratory-scale and practical gas turbine operating conditions, to understand the effect of hydrogen on the combustion characteristics of LPM combustors including combustion instabilities. The purpose of this article is to provide a review of the challenges of burning pure hydrogen and hydrogen-enriched natural gas in the context of thermoacoustic instabilities in LPM combustors based on literature available in the public domain. The primary focus is on swirl-stabilised systems which form the dominant flame stabilisation mechanism employed in low emissions stationary gas turbine combustors [20]. Both forced and self-excitation studies in fully premixed and partially-premixed systems are reviewed. Self-excited instabilities arise 'naturally' from the coupling of heat release oscillations with one of the acoustic eigenmodes of the combustor. For forced excitation studies, oscillations are generated by using a siren or loudspeaker to simulate the complex 
acoustic environment during unstable combustion in order to understand the response of a flame to oscillatory disturbances.

The rest of this article is structured as follows. A summary of the main challenges of burning hydrogen in LPM combustors is presented in Section 2. To set the context for subsequent chapters, a general overview of thermoacoustic instabilities is provided in Section 3. Section 4 discusses the effect of hydrogen enrichment on combustion dynamics. In Section 5, additional operational and geometric considerations pertaining to thermoacoustic instabilities of hydrogen flames are reviewed. Finally, the findings are summarised in Section 6 where the main insights are discussed and research gaps identified in order to provide direction for future combustion instability research in efforts to achieve $100 \%$ hydrogen combustion in gas turbines.

\section{Challenges of Burning Hydrogen in Lean Premixed Combustion Systems}

Hydrogen has different thermophysical and chemical properties in comparison to natural gas, which leads to contrasting combustion characteristics especially in the context of LPM combustion. Table 1 compares common combustion properties of hydrogen to gaseous methane. Key among these properties are its relatively higher adiabatic flame temperature, flame speed and diffusivity which pose several technical challenges to LPM combustor operation $[19,26,27]$. In this section, some of the main challenges of burning hydrogen in LPM combustors are briefly summarised. These relate to increased propensity for flashback and autoignition as well higher $\mathrm{NO}_{x}$ emissions and different thermoacoustic instability characteristics arising from its higher reactivity and burning rates.

Table 1. Thermophysical and chemical properties of hydrogen $[26,28]$.

\begin{tabular}{lcc}
\hline Property & Hydrogen & Methane \\
\hline Specific gravity at NTP ${ }^{1}$ & 0.07 & 0.55 \\
\hline Lower calorific value by mass $(\mathrm{MJ} / \mathrm{kg})$ & 119.93 & 50.02 \\
\hline Lower calorific value by volume at NTP $\left(\mathrm{MJ} / \mathrm{m}^{3}\right)$ & 10.05 & 33.36 \\
\hline Flammability limits in air $($ by volume $)$ & 4 to 75 & 5.3 to 15 \\
\hline Minimum ignition energy in air $(\mathrm{mJ})$ & 0.02 & 0.29 \\
\hline Autoignition temperature $(\mathrm{K})$ & 858 & 813 \\
\hline $\begin{array}{l}\text { Maximum adiabatic flame Temperature in air at } \\
\text { NTP }{ }^{1,2}(\mathrm{~K})\end{array}$ & 2376 & 2223 \\
\hline Maximum laminar flame speed in air at NTP $1,2(\mathrm{~cm} / \mathrm{s})$ & 306 & 37.6 \\
\hline Thermal diffusivity at NTP ${ }^{1,2}\left(\mathrm{~mm}^{2} / \mathrm{s}\right)$ & 153.26 & 23.69 \\
\hline Momentum diffusivity at $\mathrm{NTP}^{1,2}\left(\mathrm{~mm}^{2} / \mathrm{s}\right)$ & 105.77 & 16.81 \\
\hline Mass diffusivity in air at $\mathrm{NTP}^{\prime 1,2}\left(\mathrm{~mm}^{2} / \mathrm{s}\right)$ & 78.79 & 23.98 \\
\hline $\begin{array}{l}1 \\
\text { NTP }=\text { Normal Temperature and Pressure, i.e., } 2{ }^{\circ} \mathrm{C} \text { and } 101.325 \mathrm{kPa}{ }^{2} \text { Computed for this article using }\end{array}$
\end{tabular}

Flashback is the undesirable, upstream propagation of the flame front from the combustion zone into the premixing sections of the combustor as a result of an imbalance between the local turbulent flame speed and flow velocity of the reactants, wherein the former exceeds the latter [31]. Flashback can subsequently lead to localised flame holding in the premixing passages, resulting in overheating and hardware damage. The higher turbulent flame speed of hydrogen relative to natural gas increases the propensity for flashback in LPM combustors [32]. Well-researched flashback mechanisms include [33]: (i) flame propagation due to combustion instabilities, (ii) flame propagation in the core flow, (iii) flame propagation within boundary layers and (iv) combustion-induced vortex breakdown. 
The typical inlet pressures and temperatures for modern gas turbines are sufficiently high for autoignition to occur [13]. Autoignition refers to spontaneous ignition of the combustible fuel-air mixture in the premixing section in the absence of an ignition source. While the autoignition temperature of hydrogen is only marginally higher than that of methane [26], hydrogen has a significantly shorter ignition delay time $[19,34]$ hence a concern for burning hydrogen-enriched fuels in LPM combustors. The spontaneous ignition delay is the time interval available for a reactive mixture to react in the absence of an ignition source [20]. If the ignition delay time is shorter than the fuel-air mixing residence time, then autoignition can occur leading to local flame holding or flashback.

Even though burning hydrogen produces no carbon emission at the point of use, $\mathrm{NO}_{\mathrm{x}}$ emissions are a concern for hydrogen combustion due to its higher adiabatic flame temperature relative to natural gas. At typical LPM burner stoichiometry, the adiabatic flame temperature for pure hydrogen is over $150 \mathrm{~K}$ higher in comparison to methane [27]. For a fixed gas turbine configuration, this will result in higher $\mathrm{NO}_{x}$ emissions if the operating conditions are not adapted, for example, by shifting to leaner equivalence ratio $(\phi)$ [19].

Changes in fuel composition can have a significant impact on the thermoacoustic instability characteristics of LPM combustors [25]. The effect of hydrogen-enrichment on combustion instabilities is the focus of this paper and is discussed in detail in Sections 3 and 4 .

\section{Overview of Thermoacoustic Instabilities}

Constituting one of the most challenging fields of combustion research, thermoacoustic instabilities refer to undesirable, large amplitude oscillations of one or more natural acoustic modes of a combustor arising from resonant interaction between oscillatory flow and unsteady heat release processes $[23,25,35]$. The pressure oscillations can reach amplitudes of the order of a large percentage of the mean combustor static pressure [36]. Left uncontrolled, these instabilities can lead to many undesirable consequences such as component vibrations, increased heat transfer rates, flame blow-off and flashback $[25,33,37]$. Over time, the oscillations can result in substantial system deterioration while constraining the operating envelope of the engine [38] and in worst-case scenarios, lead to structural damage [39,40].

The feedback process for self-sustaining combustion instabilities is illustrated in Figure 1 [41]. Perturbations of the flow/mixture are generated through a driving process. These flow /mixture perturbations produce heat release oscillations which induce fluctuations in acoustic pressure and velocity. The acoustic oscillations in turn generate further flow/mixture perturbations, thus closing the feedback loop. For confined flames, the acoustic oscillations appear as discrete tones at one of the natural acoustic modes of the combustor [35,42]. Because combustors are highly resonant systems and unsteady combustion is an efficient source of acoustic energy, acoustic waves generated by fluctuating heat release are reflected from the walls of the combustor to produce flow unsteadiness near the flame [22,38].

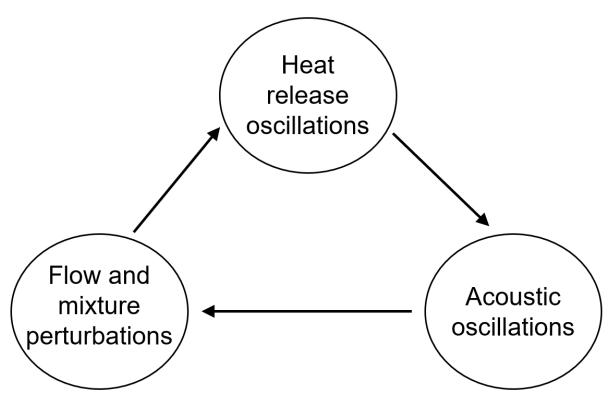

Figure 1. Feedback cycle for thermoacoustic instabilities. 
The existence of a time lag is perhaps the biggest reason for thermoacoustic instabilities in premixed combustion systems $[43,44]$. This is essentially the time it takes for a fuel particle to be convected to the reaction zone, ignited and its energy released. Systems incorporating such time delays are inherently unstable because if this time delay coincides with the convection time of a disturbance from the point of formation to the region of heat release, instabilities may occur [43]. Furthermore, LPM combustors employ little to no film cooling or dilution air along the liner walls $[20,21,45]$. This results in substantial reduction in acoustic damping in contrast to diffusion-flame combustors where secondary and dilution air provide excellent sound attenuation [20,22].

The first condition necessary for the occurrence of self-sustained combustiondriven oscillations, identified by Lord Rayleigh [46], is that the heat release fluctuations $\left(q^{\prime}\right)$ and pressure oscillations $\left(p^{\prime}\right)$ must be in phase $\left(\theta<90^{\circ}\right)$. The second condition is that the rate at which energy is transferred from the unsteady heat release process to the unstable acoustic mode must exceed the rate of acoustic energy dissipation $[47,48]$. This relationship is mathematically formulated through the modified Rayleigh criterion shown in Equation (1) [41], where $p^{\prime}(x, t), q^{\prime}(x, t), L_{i}, t, x, V$ and $T$ are, respectively, the acoustic pressure oscillations, periodic heat release oscillations, $i^{\text {th }}$ acoustic energy loss process, time, position within the combustor, combustor volume and period of oscillation. All practical combustors incorporate some form of acoustic damping such that the value of the integral in Equation (1) must exceed the damping integrated over the system volume for instability to occur [49]. Following the onset of combustion instability, the amplitude of the pressure oscillations initially grows with time at an exponential rate in the linear regime before saturating into a finite amplitude limit cycle oscillation which arises from nonlinear effects [50]. Limit cycle is the point in the oscillation cycle where the energy addition and dissipation mechanisms become amplitude dependent and the oscillation amplitude reaches its maximum value [41].

$$
\int_{V} \int_{T} p^{\prime}(x, t) q^{\prime}(x, t) d t d V \geq \int_{V} \int_{T} \sum_{i} L_{i}(x, t) d t d V
$$

Combustion instability driving mechanisms refer to those physical processes which generate flow perturbations leading to unsteadiness in the flame front and oscillatory heat release [23]. Decades of experimental, theoretical and numerical research have been devoted to the study of these driving mechanisms [51-55]. The mechanisms which lead to dynamic instabilities can be understood by examining Equation (2) [25], which relates the volumetric heat release rate $\dot{Q}$ to the heat of reaction per unit mass $q$, the density of the unburnt reactants $\rho$, the laminar burning velocity $S_{L}$ and the flame surface area per unit volume $A$. It follows that fluctuations in flame speed, heat of reaction and flame surface area can lead to unsteady heat release. For LPM combustion systems, the dominant driving mechanisms are: (i) velocity fluctuations and (ii) equivalence ratio oscillations $[32,56]$. Coupled interaction between two or more mechanisms can also occur $[54,57]$.

$$
\dot{Q}=q \rho S_{L} A
$$

Suppression of combustion instabilities can be achieved by increasing the damping in the combustion system or by shifting the phase between the pressure and heat release oscillations to a value greater than $90^{\circ}$ to break the feedback loop. Two control strategies have been employed for controlling combustion instabilities: passive and active $[24,25,56]$. Passive control methods involve fixed combustor hardware changes. Such methods primarily involve the use acoustic dampers such as Helmholtz resonators, quarter-wave tubes and perforated liners designed to damp specific frequencies excited within the combustor, fuel injector modifications to alter the convective time lag thus affecting the timescale associated with the unsteady combustion process 
and the use of diffusion/partially-premixed pilot flames to locally increase the degree of unmixedness and improve flame anchoring [58]. In active combustion instability control, certain combustion parameters are externally excited in order suppress the growth of combustion oscillations by interrupting the coupling between unsteady heat release and acoustic waves [59]. It involves measurement of a dynamic signal related to the combustion oscillations such as dynamic pressure fluctuations or chemiluminescence emissions and an actuator which dynamically modifies an input to the combustion system in response to a signal from a control algorithm [38]. In practical systems, this is mainly achieved by modulating the fuel flow to the combustor $[24,25]$.

\section{Influence of Hydrogen Enrichment on Combustion Dynamics}

Following a detailed introduction to thermoacoustic instabilities in the previous section, this section discusses the effect of hydrogen addition on dynamic instability characteristics of LPM combustors in the context of its impact on dynamic stability maps, flame structure and combustion dynamics-induced flashback.

\subsection{Effect on Stability Maps and Dynamic State Transitions}

Observations by several researchers have shown that enriching natural gas with hydrogen leads to a shift in the dynamic stability characteristics of a given combustor.

Experimental work by Janus et al. [60] investigated the effect of enriching natural gas with $25 \%$ hydrogen by volume on self-excited combustion instabilities in a fully premixed combustor operating at fixed inlet temperature. Stability maps revealed a shift in the dynamically unstable region toward lower air flow rates and equivalence ratios, with lower dynamic pressure amplitude, as a result of hydrogen addition. This was attributed to the faster reaction rates and shorter convective time scales of the methane-hydrogen mixture, which affected the phase relationship between fluctuating pressure and unsteady heat release.

In the work of Figura et al. [61], the researchers characterised self-excited combustion instabilities in a fully premixed, variable length LPM combustor operating with up to $25 \%$ hydrogen by volume blended into natural gas. Keeping the inlet temperature and Reynolds number constant for fixed combustor lengths, they found that hydrogen addition shifted the instabilities to lower equivalence ratios with reduced dynamic pressure amplitudes. This is illustrated in the stability maps plotted in Figure 2. For natural gas, the strongest instabilities were observed at $\phi=0.7$ while the instabilities occurred at $\phi=0.6$ for the $25 \%$ hydrogen blend with a lower amplitude. The second unstable region at $\phi=0.65$ for natural gas was also shifted with the addition of $25 \%$ hydrogen to $\phi=0.55$ with a much diminished amplitude.
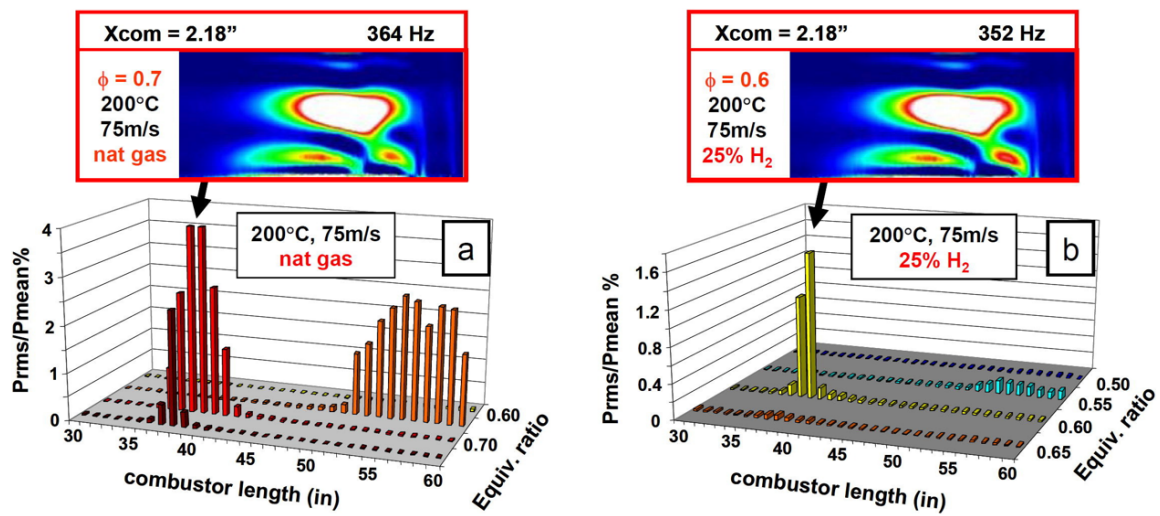

Figure 2. Stability maps and corresponding $\mathrm{CH}^{*}$ chemiluminescence flame images at inlet temperature of $200{ }^{\circ} \mathrm{C}$ and bulk inlet velocity of $75 \mathrm{~m} / \mathrm{s}$ for (a) natural gas and (b) natural gas blended with $25 \%$ hydrogen by volume. Adapted from Figura et al. [61]. 
Taamallah et al. [27,62] investigated methane flames enriched with $0 \%, 10 \%$ and $20 \%$ volumetric concentrations of hydrogen at atmospheric pressure by varying $\phi$ while keeping Reynolds number constant. Their findings showed that, in addition to extending the LBO limit, hydrogen-enriched flames experienced dynamic mode transitions at lower equivalence ratios compared to pure methane flames as shown in Figure 3. The strongest instabilities occurred at $0.67<\phi<0.75$ for $100 \%$ methane. For $10 \%$ and $20 \%$ hydrogen, the instabilities were strongest at $0.64<\phi<0.7$ and $0.6<\phi<0.65$ respectively. Similar dynamic pressure amplitudes were observed for the three fuels. This shift in the dynamically unstable region of a combustor toward lower equivalence ratios as a result of hydrogen enrichment has also been reported by other researchers [63-65]. Extension of the LBO due to the higher strain resistance of hydrogen is also consistent with findings from other studies [62,63,66,67].

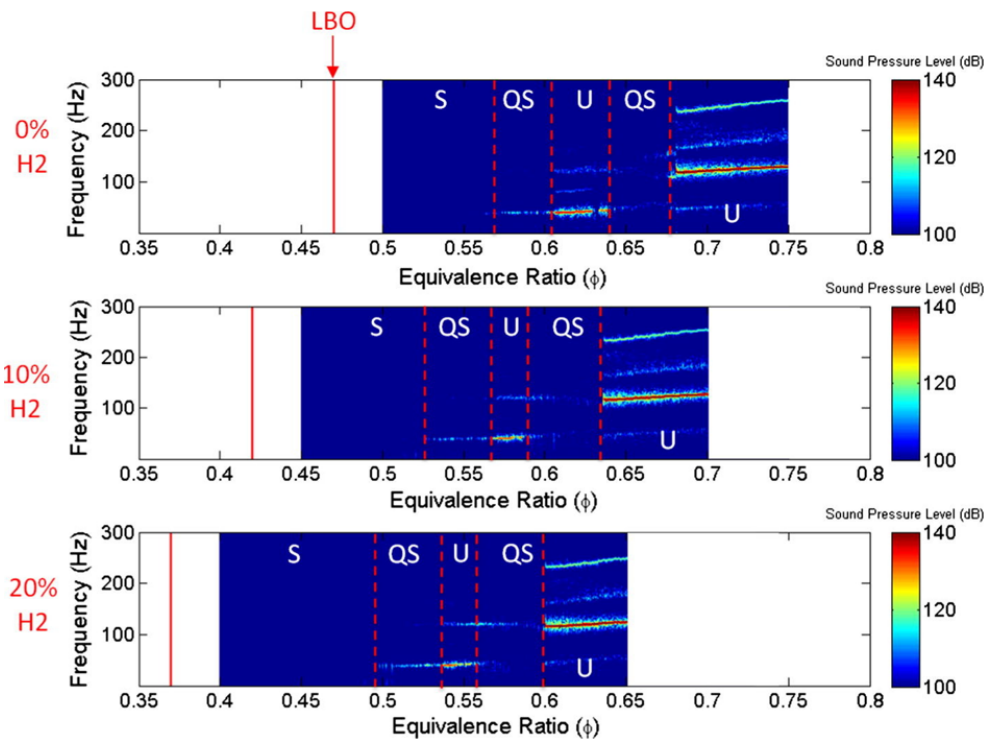

Figure 3. Dynamic stability maps of methane-hydrogen fuel blends. (S) stable, (U) unstable and (QS) quasi-stable combustion. Solid red line denotes LBO limit. The authors define quasi-stability as pressure fluctuations with relatively low amplitude. Reproduced from Taamallah et al. [27].

Transitions in dynamic stability regimes with increasing $\mathrm{H}_{2}$ content was also observed by Karlis et al. [68], who experimentally investigated self-excited combustion instabilities for blends of $\mathrm{CH}_{4}$ and $\mathrm{H}_{2}$ between $0 \%$ and $40 \%$ by volume at fixed equivalence ratio and Reynolds number. They found that the combustor was stable for $\mathrm{H}_{2}$ concentration up to $20 \%$. Increasing $\mathrm{H}_{2}$ content between $30 \%$ and $37.5 \%$ led to intermittent bursts of dynamic pressure and heat release before transitioning to high amplitude limit cycle oscillations with $40 \% \mathrm{H}_{2}$. The authors established thresholds for extinction strain rates within which the stable, intermittent and limit cycle regimes existed. Similarly, Zhang and Ratner [65] found that increasing hydrogen concentration in methane-hydrogen fuel blends altered the dynamic stability characteristics of their premixed combustor from stable to unstable, transitioning through an intermediate 'conditionally unstable' region. The study investigated methane-hydrogen fuel blends up to $40 \%$ by volume of hydrogen for a range of equivalence ratio and Reynolds number. They also observed that the instabilities were excited at lower hydrogen concentrations as equivalence ratio was increased.

Mode switching between acoustic resonant frequencies as a result of hydrogen enrichment has been reported by some authors. Lee et al. [69] studied self-excited thermoacoustic instabilities for various $\mathrm{CH}_{4} / \mathrm{H}_{2}$ flames in a partially-premixed scaleddown industrial GE7EA gas turbine combustor operated at fuel heat inputs of $40 \mathrm{~kW}$ and $50 \mathrm{~kW}$. Volumetric $\mathrm{H}_{2}$ concentration in the fuel mixture was varied between $0 \%$ 
and $100 \%$. At the $40 \mathrm{~kW}$ condition, high frequency combustion instabilities were excited with $\mathrm{H}_{2}$ content between $30 \%$ and $80 \%$. Increasing the thermal input to $50 \mathrm{~kW}$ amplified the intensity of the combustion oscillations while extending the range of $\mathrm{H}_{2}$ content required for triggering instabilities to approximately 5-100\%. Different high frequency acoustic modes were excited depending upon the hydrogen content in the fuel. Below $\sim 20 \% \mathrm{H}_{2}$, a $750 \mathrm{~Hz}$ frequency corresponding to the 3rd longitudinal mode was preferentially excited for both heat input conditions while between $\sim 20 \%$ and $\sim 80 \% \mathrm{H}_{2}$, a $1000 \mathrm{~Hz}$ frequency which corresponded to the 4th longitudinal mode was excited. The 6 th longitudinal mode instability at a frequency of around $1500 \mathrm{~Hz}$ was excited above $\sim 80 \%$ hydrogen for the $50 \mathrm{~kW}$ thermal input case only. Similar observations were reported by Park and Lee [70] and Kim et al. [71] in later investigations using the same burner. The excitation of higher frequency instabilities due to hydrogen enrichment has also been reported in other studies [64,72,73].

Wicksall and Agrawal [74] experimentally studied combustion instabilities at atmospheric pressure for methane-hydrogen fuel blends up to $40 \%$ hydrogen by volume over a range of adiabatic flame temperatures in a fully premixed combustor. At high flame temperatures, sound level measurements and peak sound intensity levels were considerably higher for the $40 \% \mathrm{H}_{2}$ blend compared to lower $\mathrm{H}_{2}$ concentrations. The authors indicated that the combustor was rendered thermoacoustically unstable with $40 \% \mathrm{H}_{2}$ in the fuel mixture. Power spectral density plots at a fixed adiabatic flame temperature revealed a transition in the frequency spectrum from a multi-modal distribution to a single, narrow peak with very high amplitude as $\mathrm{H}_{2}$ concentration was increased. With 100\% methane, two peaks at $450 \mathrm{~Hz}$ and $600 \mathrm{~Hz}$ were observed in which the latter concentrated most of the acoustic power. $\mathrm{As}_{2}$ content was increased in the fuel, a gradual shift in the total sound power from $600 \mathrm{~Hz}$ to $450 \mathrm{~Hz}$ was noticeable. When the $\mathrm{H}_{2}$ content reached $40 \%$, the $600 \mathrm{~Hz}$ frequency was totally diminished in favour of the high amplitude $450 \mathrm{~Hz}$ peak whose intensity was an order of magnitude higher compared to lower $\mathrm{H}_{2}$ concentrations.

The above studies highlight that hydrogen enrichment not only extends the LBO limit, it also leads to a shift in the dynamic instability regions toward lower equivalence ratios. This feature is intrinsically linked to the higher turbulent flame speed of hydrogen and the resulting upstream shift in flame position which alters the thermoacoustic characteristics of the combustor. The implication is that a combustor that is thermoacoustically stable could be rendered unstable and vice versa depending upon the equivalence ratio. Increasing hydrogen content can also lead to transitions from stable to unstable combustion through an intermittent regime characterised by random bursts of high amplitude limit cycle oscillations and stable aperiodic states. Mode switching between natural frequencies of the combustor, including the excitation of higher frequency instabilities, can also be triggered as a result of hydrogen enrichment.

\subsection{Effect on Flame Structure and Flame Position}

Studies by several authors have revealed correlations between changes in flame structure/flame position and the occurrence of thermoacoustic instabilities resulting from hydrogen addition.

The work of Figura et al. [61], earlier discussed in Section 4.1, is one of the first studies to highlight the effect of hydrogen addition on the relationship between flame structure and self-excited combustion instabilities. The two-dimensional chemiluminescence images in Figure 2 reveal a similar flame shape and location of the flame "centre of heat release" for both natural gas and $25 \% \mathrm{H}_{2}$ fuel mixture, even though combustion instabilities were observed at different equivalence ratios. The flame "centre of heat release" can be interpreted as the average flame location and is a complex function of flame length, flame shape, flow velocity and frequency [32]. By having the same location of the flame "centre of heat release", the two fuel mixtures exhibited 
similar convective time delays and therefore similar dynamic stability characteristics. These results led the authors to the important conclusion that flames with the same "centre of heat release" under stable conditions exhibit similar flame structures and dynamic response.

Studies by Taamallah et al. [62] and Shanbhogue et al. [75] also established a strong link between flame shapes and the onset of thermoacoustic instabilities for methane-hydrogen fuel mixtures. The authors identified distinct changes in the flame shape at the same $\phi$ where transitions in dynamic modes were observed (see Section 4.1). Testing with pure methane, $10 \% \mathrm{H}_{2}$ and $20 \% \mathrm{H}_{2}$ by volume revealed a similar sequence of flame structures from stable conditions to limit cycle oscillations as $\phi$ was increased, with very similar thermoacoustic modes and spectral characteristics. This is illustrated in Figure 4 which shows that the flame shape transitions were similar irrespective of fuel composition; the only difference being that the transitions occurred at lower equivalence ratios with increasing hydrogen content. The appearance of a flame in the outer recirculation zone (ORZ) was identified as a precursor to unstable combustion in the three cases. Shanbhogue et al. [75] demonstrated that the higher extinction strain rates of the high hydrogen mixtures was the enabling mechanism which allowed the flame to penetrate into the ORZ and stabilise at lower equivalence ratios compared to pure methane, hence the reason for the flame shape transitions at lower equivalence ratios.

Many researchers have observed that the addition of hydrogen to natural gas leads to a transition in flame shape from a V-shape to an M-shape, although with different effects on dynamic instabilities [63,72,75-77]. Referring back to Figure 4 from the work of Shanbhogue et al. [75], it can be observed that the $100 \% \mathrm{CH}_{4}$ flame at $\phi=0.58$ exhibited a V-shape and was reported as being thermoacoustically stable. At the same equivalence ratio, an M-shaped flame is observed (Figure 4) as the hydrogen concentration was increased to $10 \%$ and $20 \%$. The authors noted that these flames were fully anchored in the ORZ and were thermoacoustically unstable. The transition from a V-shaped to M-Shaped flame at lower equivalence ratios for the hydrogen flames was found to be a consequence of the higher extinction strain rates, which arise from the higher diffusivity of hydrogen compared to methane.

On the contrary, the work of Lantz et al. [72] revealed that transition to an M-shaped flame due to hydrogen enrichment in their combustor coincided with a suppression of self-excited combustion instabilities. The authors investigated natural gas flames enriched with up to $80 \%$ hydrogen by volume at atmospheric pressure using a third generation dry low emissions (DLE) burner employed by Siemens Energy in their SGT-700 and SGT-800 industrial gas turbines. Adiabatic flame temperature was fixed as the volumetric concentration of hydrogen was varied in the fuel mixture. Changes in the shape and size of the flame were observed as the hydrogen concentration in the fuel was increased. Chemiluminescence and $\mathrm{OH}$ planar laser-induced fluorescence (PLIF) images revealed that above $60 \%$ hydrogen, the flames not only propagated upstream to stabilise in the premixing section, the flame shape changed from V-shape to M-shape. The $80 \% \mathrm{H}_{2}$ flame in particular was found to be anchored on the burner tip in the ORZ. Dynamic pressure measurements revealed that the amplitude of the dominant axial mode was nearly completely suppressed with $60 \%$ hydrogen. With $80 \%$ hydrogen, the axial mode reappeared but with a much reduced amplitude compared to $100 \%$ methane. However, a higher frequency mode was also excited with $80 \%$ hydrogen which the authors suggested was a transverse mode instability. The lower pressure amplitudes observed for the hydrogen-rich flame coincided with a reduction in the observed flame front fluctuations compared to the pure natural gas flame. Subash et al. [76] extended the work of Lantz et al. [72] by comparing the dynamics of pure natural gas and pure hydrogen flames using an optimised version of the same DLE burner. The pure hydrogen flame was shorter, more compact and stabilised closer to the burner exit compared to the pure methane flame. The flame 
shape was also M-shaped, penetrating into the ORZ, as opposed to the V-shaped methane flame. Consistent with previous findings [72,78], they found that firing pure hydrogen damped the dominant axial mode relative to the pure methane flame. A higher frequency mode, albeit with a relatively smaller amplitude, could also be observed in the FFT spectrum. Using probability density maps of $\mathrm{OH}$ gradients as an indicator of flame front fluctuations, the authors observed that the pure hydrogen flame exhibited significantly lower flame front fluctuations in the inner shear layer compared to the pure natural gas flame.

Experimental work at atmospheric pressure conditions by Kim et al. [77] provided great insight into the forced flame response and structure of hydrogen-enriched natural gas. The study investigated blends of natural gas with $\mathrm{H}_{2}$ up to $60 \%$ by volume. Observations of stable flame shapes, obtained using $\mathrm{CH}^{*}$ chemiluminescence imaging at fixed inlet temperature and velocity, revealed a transition from a V-shaped flame to an $\mathrm{M}$-shaped flame with increasing $\mathrm{H}_{2}$ concentration. The same flame shape transition was also found to occur at a higher equivalence ratio for the pure methane flame due to higher burning velocity. This is a clear indication that the higher burning velocity of hydrogen was responsible for the occurrence of the flame structure transition at a lower equivalence ratio. A decrease in the gain and phase of the flame transfer function (FTF) was found for the hydrogen blends relative to the pure natural gas flames at low forcing amplitudes. Figure 5 plots the gain and phase of the FTF for pure methane and a blend of $85 \%$ methane with $15 \%$ hydrogen to illustrate the effect of hydrogen addition. The researchers identified this as a characteristic feature of the shorter, compact M-shaped flames that allows them to damp flow perturbations in the combustor, with the implication that hydrogen-enriched natural gas flames could be more dynamically stable than pure natural gas flames. They also noted, however, that the M-shaped hydrogen flames could still couple with higher frequency modes of the combustor.

\begin{tabular}{|c|c|c|c|}
\hline$\phi$ & $100 \% \mathrm{CH}_{4}$ & $90 \% \mathrm{CH}_{4} / 10 \% \mathrm{H}_{2}$ & $80 \% \mathrm{CH}_{4} / 20 \% \mathrm{H}$ \\
\hline 0.48 & & & \\
\hline 0.51 & & & \\
\hline 0.53 & & & \\
\hline 0.56 & & & \\
\hline 0.58 & & & \\
\hline 0.62 & & |ख & \\
\hline 0.63 & & & \\
\hline
\end{tabular}

Figure 4. Flame shape transitions as function of equivalence ratio for pure methane, $10 \% \mathrm{H}_{2}$ and $20 \% \mathrm{H}_{2}$ by volume. Reproduced from Shanbhogue et al. [75]. 


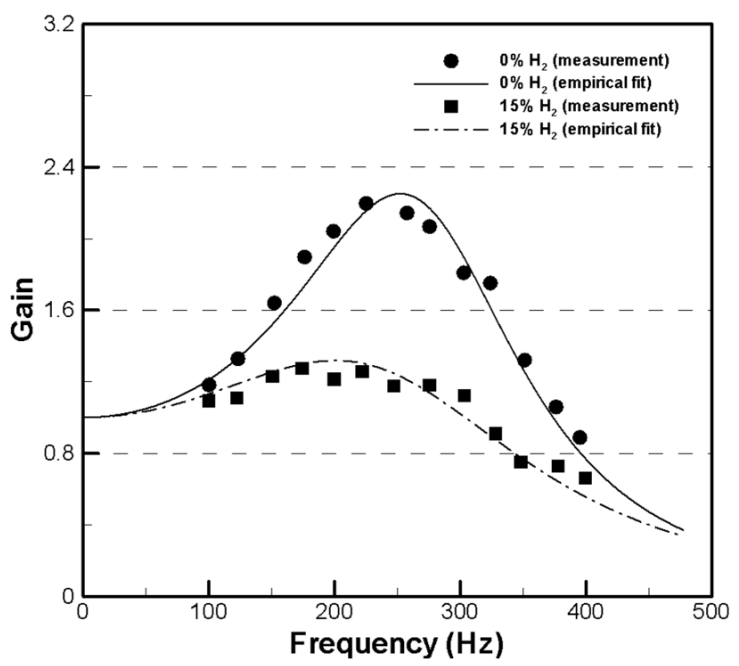

(a) Gain

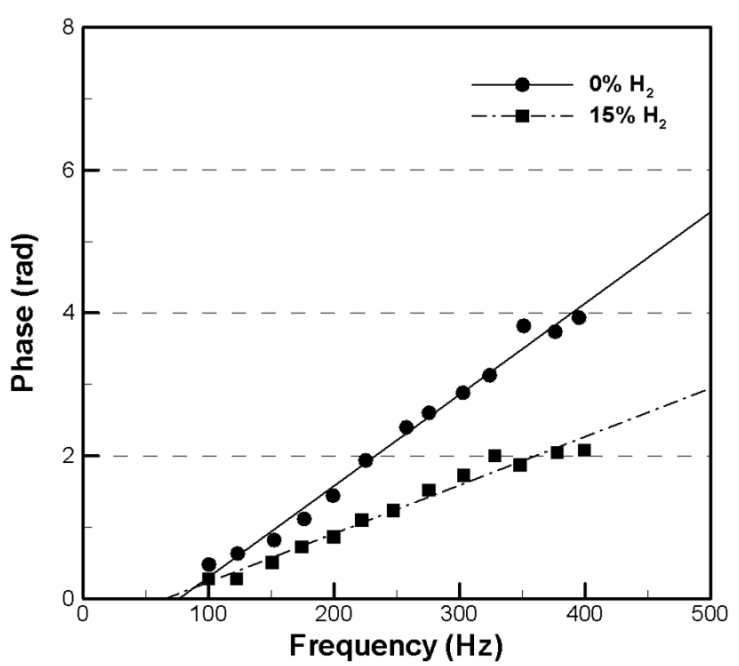

(b) Phase

Figure 5. Influence of hydrogen enrichment on gain and phase of FTF at low forcing amplitude. Operating conditions: inlet temperature $=200{ }^{\circ} \mathrm{C}$, bulk velocity $=60 \mathrm{~m} / \mathrm{s}$, equivalence ratio $=0.6$. Adapted from Kim [79].

In contrast to the aforementioned studies, experimental work by Ge et al. [80] found that hydrogen-enrichment resulted in a transition from an unstable M-shaped flame to a stable V-shaped flame. The researchers investigated the combustion performance of hydrogen-enriched natural gas at atmospheric pressure conditions using a radially staged, partially-premixed DLE burner with both main and pilot fuel streams operational. Hydrogen concentrations up to $26 \%$ by volume were tested at fixed thermal output while keeping the pilot to main fuel ratio fixed at $11 \%$ and $89 \%$ respectively. Flame imaging revealed a more compact flame as hydrogen concentration was increased above $11 \%$. With increasing $\mathrm{H}_{2}$ content, the flame in the ORZ was found to gradually diminish before disappearing as the combustor became more stable. A 75\% drop in the dynamic pressure amplitude was observed with $\mathrm{H}_{2}$ content greater than $5 \%$. These observations coincided with a marked decrease in the value of the Rayleigh Index (RI) in the ORZ suggesting that the presence of a flame in the ORZ may have been the reason for instability in the natural gas flame. The addition of hydrogen suppressed the instability through the action of altering the flame structure and changing the flame shape from an unstable M-shaped flame anchored in the ORZ to a stable V-shaped flame. The contradictory flame shape transition in this study may be due to the high pilot fuel percentage used in the experiments.

Forced response studies for hydrogen-enriched flames were also carried out by Wang et al. [81]. The effect of increasing hydrogen content in methane, up to $40 \%$ by volume, on combustion instability was investigated at a low forcing amplitude over a range of acoustic forcing frequencies. In the frequency range of $170-240 \mathrm{~Hz}$, the gain of the FTF was found to decrease with hydrogen addition. An increase in the phase lag between heat release and velocity fluctuations was observed, indicating a damping effect. Flow field visualisation, using particle image velocimetry (PIV) and heat release rate imaging using $\mathrm{CH}^{*}$ chemiluminescence, at a forcing frequency of $180 \mathrm{~Hz}$ revealed that flame-vortex interaction was diminished as hydrogen content was increased. As shown in Figure 6a, large-scale vortices shed from the burner outlet reduced in size as hydrogen content increased, thus reducing their ability to roll up the flame and enhance the heat release rates leading to weakened combustion instability. Within the frequency range of $110-160 \mathrm{~Hz}$, however, the authors reported an increase in the gain and decrease in the phase of the FTF with increasing hydrogen content, indicating a higher heat release response to velocity oscillations which enhanced combustion instability. Flow field visualisation, shown in Figure 6b, revealed greater interaction between large-scale coherent structures shed from the burner outlet and the flame, 

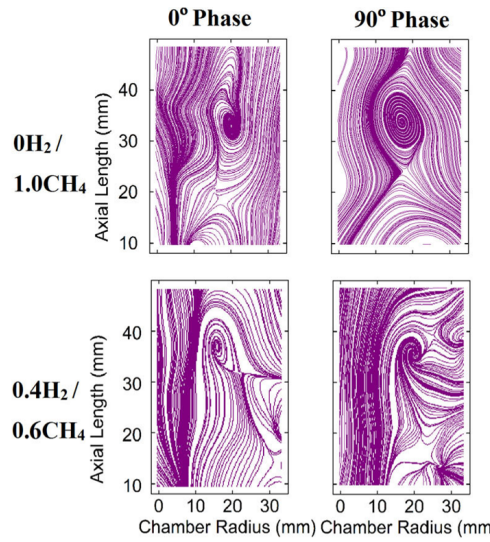

(a) $180 \mathrm{~Hz}$ leading to greater flame roll-up and heat release rate oscillations. The vortex structures became bigger in size with increasing hydrogen in the fuel mixture. This study shows that hydrogen addition can have a significant influence on flame-vortex interaction which can alter the dynamic state of a combustor.

Figure 6. Flow field visualisation showing effect of hydrogen enrichment on suppressing (a) and enhancing (b) flame-vortex interaction dynamics at two forcing frequencies. Adapted from Wang et al. [81].

The work of Zhang and Ratner [65] investigated methane-hydrogen fuel blends up to $40 \%$ by volume for a range of equivalence ratio and Reynolds number with the primary aim of understanding the flame front characteristics during self-excited combustion instabilities. Stable flame images, analysed using OH PLIF, revealed that hydrogen addition induced more flame front wrinkling. For the unstable flames, hydrogen addition was observed to enhance flame-vortex interaction leading to stronger coupling between heat release oscillations and unsteady pressure fluctuations. The local flame surface area was shown to increase with increasing hydrogen content in the fuel mixture. This is a very important finding because variation in flame surface area can have a profound impact on heat release rate and thus impact thermoacoustic instabilities [25,43].

Lee et al. [69] also observed that combustion instabilities, driven by flame-vortex interaction, were excited due to hydrogen enrichment. They investigated the effect of varying the $\mathrm{H}_{2}$ concentration between $0 \%$ and $100 \%$ by volume where they found that increasing the hydrogen content above $5 \%$ triggered high combustion instabilities. Time-averaged $\mathrm{OH}^{*}$ chemiluminescence images showed that the flame became narrower and more compact as $\mathrm{H}_{2}$ content was progressively increased in the fuel mixture. Using proper orthogonal decomposition (POD) analysis, the flame oscillations were found to be generated by distinct coherent structures and large-scale flame roll-up. Two-dimensional RI maps, which provide a visual representation of regions of thermoacoustic instability driving and damping, showed that the highest positive RI region (strongest instability driving) was shifted closer to the nozzle as hydrogen content was increased. Their findings showed that hydrogen addition in the fuel affected the locations and intensity of combustion instability driving and damping.

The effect of hydrogen enrichment on combustion instabilities has also been studied in low swirl injector (LSI) flames. The LSI burner does not exhibit vortex breakdown with a central recirculation zone (CRZ) for flame stabilisation like conventional swirl-stabilised burners; rather the key aerodynamic feature for flame stabilisation is a non-swirling centre flow which inhibits vortex breakdown and promotes the formation of a central divergent zone, thereby creating a lifted flame [82]. Therkelsen et al. [64] experimentally compared the dynamic instability behaviours of self-excited LSI flames burning $100 \% \mathrm{CH}_{4}$ and a volumetric blend of $10 \% \mathrm{CH}_{4}$ with $90 \% \mathrm{H}_{2}$ at atmospheric pressure. Flame imaging revealed a lifted, deep-bowl shape 
for the $\mathrm{CH}_{4}$ flame while the $90 \% \mathrm{H}_{2}$ flame was anchored to the burner rim with a characteristic M-shape. For the $\mathrm{CH}_{4}$ flame, coherent flame motions were observed below the trailing edge of the flame in the outer shear layer (OSL) only whereas for the $\mathrm{H}_{2}$ flame, large scale vortices were observed throughout the flame front including in the central divergent zone. Flame oscillation frequencies for both flames, derived from POD analysis, were found to be consistent with the dominant peaks in the acoustic pressure spectra, clearly indicating thermoacoustic coupling. Davis et al. [83] extended the work of Therkelsen et al. [64] to better understand the unsteady flow structures and instability driving mechanisms. Using PIV, the flow fields for both $100 \% \mathrm{CH}_{4}$ and $90 \% \mathrm{H}_{2}$ flames were found to be dominated by vortex shedding from the burner rim where the former burned intermittently while the latter burned consistently. Different instability driving mechanisms were identified for the two flames. Vortex roll-up in the OSL was reported as the main driving mechanism in the $\mathrm{CH}_{4}$ flame, whereas merging of the reacting rolled-up vortices in the OSL with the central part of the flame was the key mechanism for the high $\mathrm{H}_{2}$ flame. Hydrogen addition therefore altered the combustion instability driving mechanism in the combustor.

The above studies have shown that the higher reactivity of hydrogen-enriched fuels can have a significant influence on flame structure and flame position as well as flame-vortex interaction which can alter the thermoacoustic state of a combustor. Hydrogen addition can also change the instability driving mechanism of a combustor.

\subsection{Effect on Flashback}

Strong correlations between periodic flashback events and thermoacoustic instabilities in methane-hydrogen fuel mixtures have been reported in literature. Tuncer et al. [84] experimentally investigated methane-hydrogen fuel blends with up to $50 \% \mathrm{H}_{2}$ by volume in a fully premixed burner at atmospheric pressure conditions. Hydrogen addition was found to increase the measured root mean square (RMS) pressure amplitudes and cause an abrupt shift in the dominant frequency to a lower frequency. This transition occurred around $20 \%$ to $25 \% \mathrm{H}_{2}$ and was found to coincide with the conditions at which flashback was initiated. The spectra for pressure, heat release and flashback are plotted in Figure 7 which shows no flashback for the pure methane case and a $40 \mathrm{~Hz}$ flashback signal for the $50 \% \mathrm{H}_{2}$ flame. The periodic flashback signal was found to be in phase with the pressure and heat release oscillations at the higher $\mathrm{H}_{2}$ concentrations and occurred at the pressure oscillation frequency. The understanding is that the flame oscillated back and forth inside the premixer and produced heat release oscillations at the flashback frequency, which then coupled to one of the acoustic modes of the combustor.

García-Armingol and Ballester [85] also observed coupling between flashback and combustor acoustics with a volumetric blend of $50 \% \mathrm{CH}_{4}: 50 \% \mathrm{H}_{2}$. Though no mode shift was identified as in the work of Tuncer et al. [84] reviewed above, the RMS pressure fluctuations for the $50 \% \mathrm{H}_{2}$ blend was two orders of magnitude higher compared to $100 \%$ methane. Periodic flashback events during an instability cycle, as captured by phase-resolved $\mathrm{OH}^{*}$ chemiluminescence images, corroborated the coupling between combustion instabilities and oscillating flashback events.

These studies not only highlight the increased propensity for flashback induced by thermoacoustic instabilities as a result of hydrogen addition to natural gas, they also reveal the potential for coupling of periodic flashback events with combustion instabilities. 


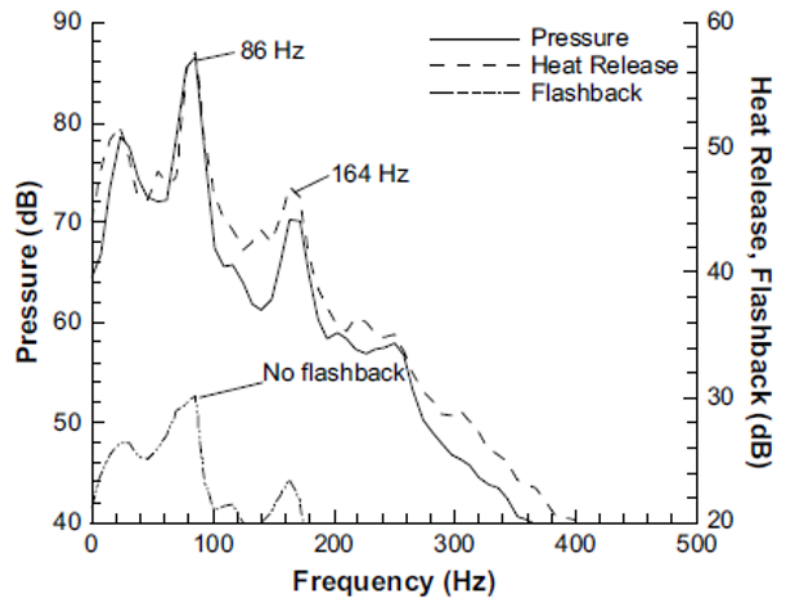

(a) Pure methane

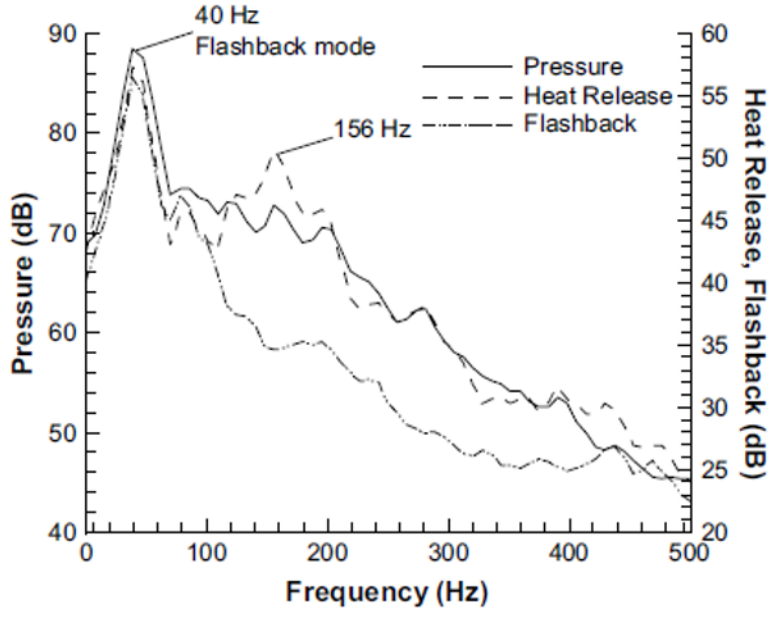

(b) $50 \% \mathrm{H}_{2}$ by volume

Figure 7. Flashback induced by combustion instabilities due to hydrogen enrichment. Pressure, heat release and flashback spectra at $\phi=0.7$. Reproduced from Tuncer et al. [84].

\section{Additional Combustion Instability Considerations for High Hydrogen Fuels}

In this section, other operational and geometric considerations pertaining to combustion instabilities for pure hydrogen and hydrogen-enriched natural gas are discussed. Specifically, combustion instability studies of hydrogen flames at elevated pressure conditions including practical gas turbine operating conditions are reviewed. The effect of piloting on the dynamics of hydrogen flames and the few available studies relating to thermoacoustic instabilities in micromix burners are also discussed.

\subsection{Elevated Pressure}

Combustion instabilities for hydrogen-enriched flames have been investigated at elevated pressure conditions. Zhang and Ratner [65] carried out combustion instability studies for methane-hydrogen flames at atmospheric pressure, 2 bar and 3 bar conditions for blends of up to $40 \%$ hydrogen by volume over a range of equivalence ratio and Reynolds number. At the same operating pressure, OH PLIF images revealed more flame front wrinkling with increasing hydrogen content in the fuel mixture. For the same hydrogen concentration, increasing the operating pressure was found to also enhance flame front wrinkling. Figure 8 shows the effect of pressure on the dynamic stability of the hydrogen-enriched fuel mixtures for equivalence ratios of 0.7 and 0.8 at a fixed bulk inlet velocity of $5 \mathrm{~m} / \mathrm{s}$. At both equivalence ratios, increasing the combustor pressure was found to lower the concentration of hydrogen required to trigger the combustion instabilities. This effect was more pronounced as equivalence ratio was increased from 0.7 to 0.8 due to the increase in turbulent burning velocity. Investigation by Emadi et al. [67] also found that elevated combustor pressure induced more flame front wrinkling for methane-hydrogen fuel blends compared to pure methane.

Runyon et al. [86] compared the effect of elevated pressure on self-excited thermoacoustic instabilities for fully premixed pure methane and hydrogen-enriched flames. The methane/hydrogen fuel mixture was made up of $85 \% \mathrm{CH}_{4}$ and $15 \% \mathrm{H}_{2}$ by volume. Both flames were operated at an equivalence ratio of 0.55 and pressures ranging from 1.1 bar to 3.3 bar. In order to maintain similar flow fields, a constant non-dimensional mass flow was maintained with increasing pressure such that only the effects of turbulence (increased pressure) and thermochemistry (hydrogen addition) can be attributed to any observed changes in flame structure. Results showed that both flames were acoustically coupled at the resonant frequency of the combustor. Elevating the pressure resulted in an increase in dynamic pressure amplitudes for 
both flames; however lower amplitudes were measured for the hydrogen-enriched flame relative to pure methane. Chemiluminescence imaging revealed higher heat release rates with increasing combustor pressure for both fuels, which explains the higher pressure fluctuations. With increasing combustor pressure, the pure methane flame became increasingly stretched with a thickening of the mean flame brush but with no appreciable change in flame position. In contrast, the hydrogen-enriched flame was more resistant to aerodynamic stretch and was stabilised further upstream closer to the burner outlet with a reduction in the thickness of the mean reaction zone. Increasing the combustor pressure was observed to shift the flame even further upstream.

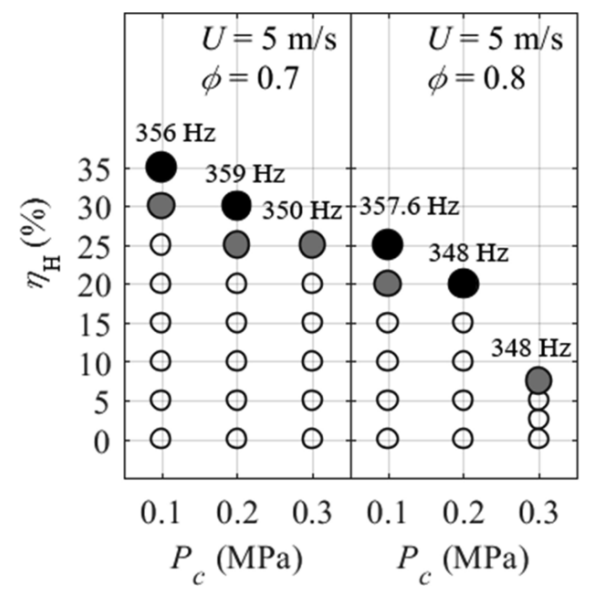

Figure 8. Dynamic instability maps for hydrogen concentration as function of combustor pressure. Reproduced from Zhang and Ratner [65].

Some gas turbine manufacturers have reported studies of combustion instabilities for hydrogen and hydrogen-rich flames in practical gas turbine combustors operating at pressurised engine conditions . Lam and Parsania [87] investigated the combustion performance of the Siemens Energy SGT-400 industrial gas turbine combustor burning blends of natural gas and up to $20 \%$ hydrogen by volume at full engine pressure and temperature. A sharper rise in the amplitude of combustion oscillations with increasing inlet pressure and combustor exit temperature was found for the hydrogen enriched fuels. At the same full load firing temperature, the RMS pressure fluctuations were reported to be three times higher compared to $100 \%$ natural gas operation. Prior high speed imaging at atmospheric pressure using the same combustor [88] showed a more compact $\mathrm{H}_{2}$ flame compared to the methane flame with more intense burning and unsteady heat release characteristics. This indicates that hydrogen addition not only rendered the combustor unstable, the effect was exacerbated with increasing pressure. Mitsubishi Heavy Industries Ltd. [89] tested blends of natural gas with up to $30 \% \mathrm{H}_{2}$ by volume in a single combustor rig at simulated J-class gas turbine firing conditions with only a small decrease in the amplitude of the resonant frequency. Ansaldo Energia [90] demonstrated the capability of operating their GT36 constant pressure sequential combustor with volumetric blends of natural gas and hydrogen ranging from $0 \%$ to $100 \%$ hydrogen. While still within their design limits, the amplitude of the dominant longitudinal mode instability was shown to increase by a factor of four with hydrogen content above $30 \%$. The amplitude of the higher frequency transverse thermoacoustic mode was observed to slightly decrease above $30 \%$ hydrogen.

Using Large Eddy Simulation (LES), Moëll et al. [73] simulated the effect of hydrogen enrichment on combustion instabilities in the third generation DLE burner used by Siemens Energy in the SGT- 800 industrial gas turbine. The computational model was based on an experimental test rig which has been used for various studies $[72,76,88]$. The study [73] compared the flame dynamics of $100 \% \mathrm{CH}_{4}$ with a blend 
of $70 \% \mathrm{CH}_{4}$ and $30 \% \mathrm{H}_{2}$ by volume at the same adiabatic flame temperature. The FFT spectrum showed that the two fuels excited the same dominant longitudinal acoustic modes. The hydrogen-enriched fuel resulted in a one-third decrease in the amplitude of the lower frequency mode, which was found to be excited due to strong interaction between the premixed pilot flame and the pressure field in the combustion chamber. However, the amplitude of the higher frequency mode was doubled as a result of hydrogen addition. The authors [73] have not reported the mechanism responsible for the excitation of the higher frequency resonant mode.

The above studies indicate that combustion instabilities in hydrogen-enriched flames can be further amplified due to an increase in combustor operating pressure. Importantly, research suggests that the concentration of hydrogen required to trigger the dynamic instabilities is lowered as pressure is elevated. It is also clear, however, that whether a combustor is stabilised or destabilised as a result of hydrogen enrichment at elevated pressure is very much dependent upon the specific combustor design and operational parameters.

\subsection{Pilot/Secondary Fuel Injection}

The use of pilot fuel injection as a passive control strategy for suppressing combustion instabilities has been introduced in Section 3. The effect of pilot fuel on the dynamic stability characteristics of hydrogen-enriched natural gas flames has been reported in literature.

Lam and Parsania [87] compared the effect of pilot fuel on combustion instabilities as a function of volumetric hydrogen concentration in the Siemens Energy SGT-400 DLE combustor operating at engine full load conditions. Above $14 \%$ hydrogen content, the authors found that increasing the pilot split, defined as the ratio of pilot fuel to total fuel, increased the amplitude of the resonant acoustic mode. Below $14 \%$ hydrogen, no effect of increasing pilot split was observed.

Subash et al. [76] investigated the effect of pilot fuel injection on the flame structure of various natural gas/hydrogen fuel mixtures up $80 \%$ hydrogen by volume in an industrial DLE burner. This was achieved by injecting 3\% of the total fuel mixture through pilot fuel injection holes distributed around the circumference of the burner outlet to form mini-diffusion flames. In the absence of pilot fuel, the flames were stabilised in the ORZ as M-shaped flames but were not anchored to the burner tip. Addition of the pilot fuel was found to increase the $\mathrm{OH}$ signal in both the $\mathrm{CRZ}$ and ORZ and the flame was observed to anchor on the burner tip. Pilot addition therefore enhanced the flame's resistance to extinction allowing it to anchor on the burner tip. Although no report of the effect on dynamic pressure was provided, the change in flame stabilisation and increased heat release rate is expected to have an impact the flame's dynamic response.

The work of Oztarlik et al. [91] is particularly instructive in improving our understanding of suppressing combustion instabilities in swirl-stabilised flames using minute quantities of pure hydrogen as a pilot diffusion flame. Comparisons with piloting using pure methane and fully premixing the same quantity of hydrogen in the main fuel stream showed that piloting with pure hydrogen had significant advantages in suppressing combustion instabilities. Using $3.3 \% \mathrm{H}_{2}$ by volume as pilot fuel, which corresponded to $1 \%$ thermal power, the number of unstable points in the dynamic stability map was reduced by a third. The number of unstable points was further reduced with $6.6 \% \mathrm{H}_{2}$. Flame visualisation of stable flames showed that the hydrogen piloted flames reduced the flame height with a redistribution of the heat release toward the root of the flame, which the authors implied to be the reason for the different flame response. The gain and phase of the FTF were significantly affected by piloting using pure hydrogen, whereas other injection strategies had a negligible impact on the flame response. 
The above studies demonstrate that the injection of pilot fuel, either as pure hydrogen or as a blend with natural gas, can impact the dynamic instability characteristics of hydrogen-enriched flames.

\subsection{Micromix Combustion}

In efforts to achieve $100 \%$ hydrogen combustion, many gas turbine manufacturers are focusing their combustor developments on micromix combustion to eliminate the risk of flashback while achieving low $\mathrm{NO}_{\mathrm{x}}$ emissions [17,92-94]. In contrast to conventional swirl-stabilised LPM combustors, micromix combustors consist of a large number of small-scale, closely spaced injectors which result in an array of distributed, compact flames with small recirculation zones. The primary objective is to reduce the distance within which fuel and air are mixed [95]. While some micromix concepts feature short premixing sections to promote rapid premixing time scales $[92,93,96]$, other designs feature small-scale jet-in-crossflow arrangements to ensure fast and intense mixing of non-premixed fuel and air while achieving good aerodynamic flame stabilisation [97]. Both concepts, examples of which are shown in Figure 9, result in miniaturised flames with very short residence time of reactants in the flame. The improved $\mathrm{NO}_{\mathrm{x}}$ emissions performance and increased flashback resistance of such novel burners have been demonstrated [92-95]. Consequently, researchers are studying the dynamic instability characteristics of these combustor architectures in the context of pure hydrogen and hydrogen-enriched natural gas flames.

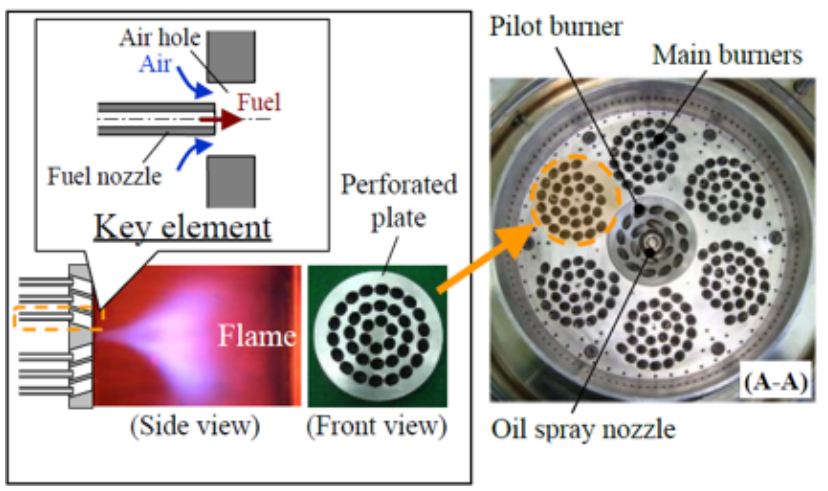

(a)

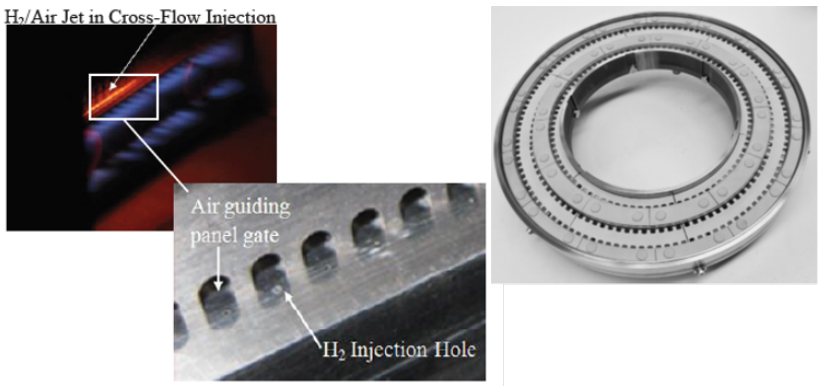

(b)

Figure 9. Types of micromix combustor concepts. (a) Premixed concept developed by Mitsubishi Hitachi Power Systems Ltd. [93]. (b) Jet-in-crossflow concept developed by Aachen University and Kawasaki Heavy Industries Ltd. [94,97,98].

Lee and Kim [96] investigated self-excited combustion instabilities in a micromix combustor, comprising an array of 60 fully premixed nozzles, to understand the key differences in flame dynamics between lean premixed hydrogen flames and methane flames. $100 \% \mathrm{CH}_{4}$ and $100 \% \mathrm{H}_{2}$ flames were studied at fixed inlet temperature and Reynolds number over a range of adiabatic flame temperatures and combustor lengths. Flame images taken under thermoacoustically stable conditions revealed that the $\mathrm{CH}_{4}$ flames were characterised by interactions between neighbouring flames, with very wrinkled flame surfaces and irregular detachment from the nozzle exit. The hydrogen flames, on the other hand, formed very compact reaction zones stabilised at each nozzle exit, devoid of interaction with adjacent flames. Analysis of thermoacoustically unstable flames revealed that the hydrogen flames preferentially excited several higher order resonant modes as the combustor length was varied. The methane flames, however, only excited the first longitudinal acoustic mode of the combustor and with lower amplitudes compared to the hydrogen flames. Figure 10a,b show the differences in dominant acoustic modes excited by the two flames as a function of combustor length for two adiabatic flame temperature conditions. Flame imaging revealed that the two flames exhibited radically different oscillatory motions during limit cycle 
oscillations as shown in the peak heat release plots in Figure 10c,d. The methane flames merged together to form a large-scale global oscillation whereas the compact hydrogen flames oscillated in isolation in the vicinity of the burner exit without any flame-to-flame interaction. From instantaneous OH PLIF images, the authors identified flame annihilation [99] as the main instability driving mechanism for the compact hydrogen flames.

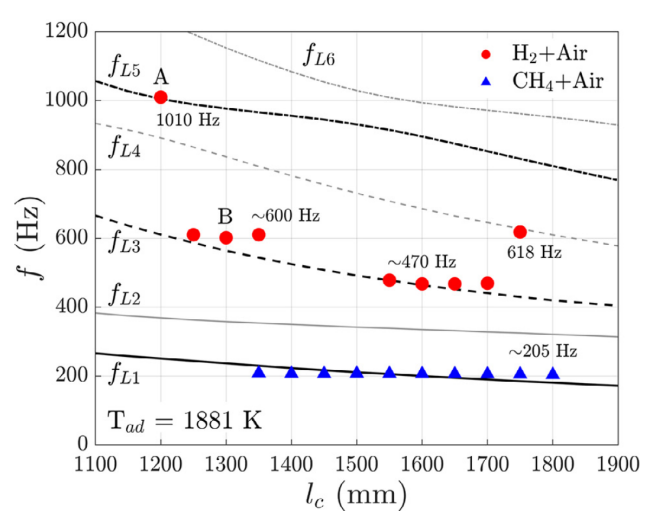

(a)

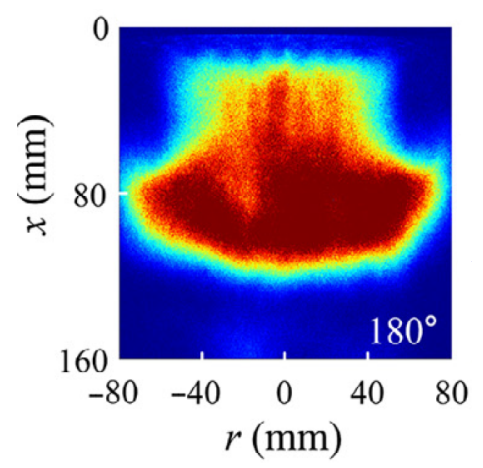

(c)

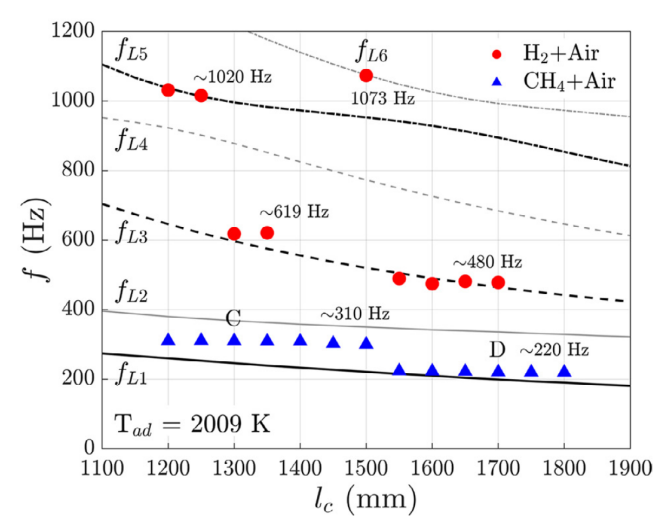

(b)

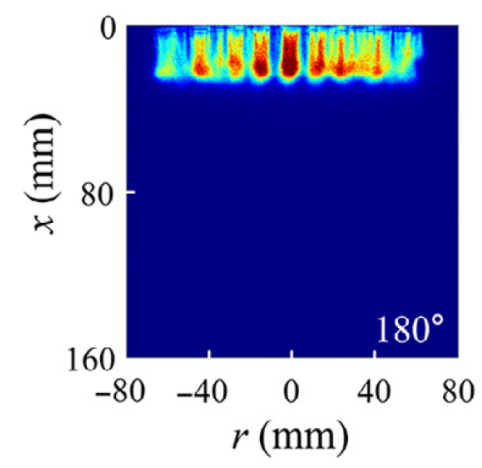

(d)

Figure 10. Combustion dynamics of hydrogen flames in a micromix combustor. Top row-comparison of measured dominant combustion instability frequencies for hydrogen and methane flames as a function of combustor length for adiabatic flame temperatures of (a) $1881 \mathrm{~K}$ and (b) $2009 \mathrm{~K}$. Bottom row-comparison of peak $\mathrm{OH}^{*}$ chemiluminescence intensities during limit cycle oscillation for (c) methane flames and (d) hydrogen flames. Flow direction is from top to bottom. Adapted from Lee and Kim [96].

McClure et al. [100] numerically investigated the forced response of hydrogen micro-diffusion flames using a single injector element in a jet-in-crossflow arrangement. FTF results, computed using steady-state Reynolds-Averaged Navier-Stokes simulation, showed that the gain of the FTF did not decrease substantially until very high frequencies $(>2000 \mathrm{~Hz})$. This is unlike typical FTF observations in conventional LPM combustors burning natural gas [99,101-103]. This suggests that the hydrogen flame is able to amplify thermoacoustic oscillations over a wider range of frequencies. It also indicates that the hydrogen micromix combustor may be more susceptible to higher frequency combustion instabilities.

From these studies, it can be inferred that firing micromix combustors with hydrogen has the potential to excite higher frequency combustion instabilities which may lead to accelerated hardware damage without any mitigation strategies.

\section{Summary and Concluding Remarks}

It is clear from this review article that the combustion of pure hydrogen and hydrogen-enriched natural gas can have a profound impact on the thermoacoustic in- 
stability characteristics of LPM gas turbine combustors. The higher reactivity of hydrogen compared to natural gas leads to differences in flame stabilisation, topology and dynamics. Whether a combustor is rendered thermoacoustically stable or unstable as a result of hydrogen addition is very much dependent upon the specific design of the combustor and its operational parameters. However, recognition of the effects of hydrogen on thermoacoustics and factoring these implications in the design and operation of LPM combustors is of paramount importance. From the preceding sections, the following insights can be drawn.

- Due to higher turbulent flame speeds, pure hydrogen and hydrogen-enriched natural gas result in compact flames which are shifted upstream closer to the burner outlet in comparison to pure natural gas flames. As the flame position is shifted upstream, so does the flame "centre of heat release". The shorter convective timescale alters the phase relationship between unsteady heat release and pressure fluctuations, thus affecting the dynamic instability characteristics of the combustor. Flame position therefore plays a crucial role in determining the dynamic state of hydrogen and hydrogen-enriched natural gas flames.

- Hydrogen enrichment has been reported to shift regions of thermoacoustic instabilities to lower equivalence ratios/flame temperatures. This implies that a gas turbine combustor that is dynamically stable at a given equivalence ratio/flame temperature may be rendered dynamically unstable and vice versa as a result of hydrogen addition. This may also have implications on attempts to achieve lower $\mathrm{NO}_{x}$ emissions by exploiting the benefit of sustaining combustion at lower equivalence ratios with hydrogen addition.

- Mode switching between acoustic resonant frequencies can occur in LPM combustors as a result of burning hydrogen or hydrogen-enriched natural gas. This can have an impact on extant combustion instability control strategies developed for natural gas operation. The excitation of higher frequency instabilities has also been reported, which can lead to accelerated structural damage if left uncontrolled.

- It has been observed that hydrogen addition can lead to regions of intermittent dynamics in the transition between dynamically stable and unstable combustion. Intermittency is an active area of combustion instability research where the phenomenon is exploited as a precursor to impending combustion instability. Extending these studies to hydrogen combustion would help in the development of predictive algorithms that could detect and actively control combustion instabilities.

- Several researchers have reported a change in flame shape from a V-shaped to an M-shaped flame as a result of hydrogen enrichment, with different consequences on combustion instabilities. There is a consensus that this flame shape transition is due to the higher extinction strain rates of the fuel mixtures containing hydrogen, arising from its higher diffusivity, which enables the flames to propagate through the velocity gradients of the outer shear layer and into the ORZ. Hydrogen has also been shown to alter the flame-vortex interaction dynamics as well as instability driving mechanism in LPM combustors. These can influence the thermoacoustic state of a combustor.

- Depending upon the forcing frequency, hydrogen can have a significant impact on the forced response characteristics of a combustor. However, there is a gap in the understanding of the nonlinear response of hydrogen flames in swirl-stabilised LPM combustors. More research is required in this field in order to develop models that can accurately predict the limit cycle behaviour of combustors burning hydrogen and hydrogen-enriched natural gas fuels.

- Hydrogen-enrichment has the potential to increase the propensity for combustion dynamics-induced flashback. It can also promote the coupling between periodic flashback events and thermoacoustic instabilities. 
- $\quad$ Elevated combustor operating pressure can amplify combustion instabilities in hydrogen-enriched flames while lowering the hydrogen content in the fuel mixture required to excite the dynamics. The latter observation is the more relevant finding for this discourse. Firstly, it indicates that atmospheric test results of hydrogen concentrations at which combustion instabilities occur cannot be directly applied or extrapolated to pressurised conditions. Secondly, as gas turbines become more efficient due to higher pressure ratios, the concentration of hydrogen required to trigger combustion instabilities is likely to be lower. Increasing combustor operating pressure has also been reported to induce more flame front wrinkling in hydrogen-enriched natural gas flames compared to pure natural gas flames which has an impact on thermoacoustic instabilities. Currently, detailed elevated pressure studies of combustion instabilities in practical combustor geometries are, generally, very limited. Hydrogen flames at practical gas turbine operating conditions should be included in future research efforts to close this gap.

- Pure hydrogen injection in minute quantities, as a pilot diffusion flame, has been shown to have potential for suppressing combustion instabilities. More work is required in this area in the context of swirl-stabilised flames to better understand the flame dynamics, impact on dynamic stability maps over a wide range of operating conditions and the best injection strategies for achieving an optimal compromise between combustion instabilities and $\mathrm{NO}_{\mathrm{x}}$ emissions.

- Micromix combustion technology is evolving as a novel burner concept to enable $100 \%$ hydrogen combustion in gas turbines. The few published studies on combustion instabilities have highlighted the tendency to excite higher frequency dynamics in these combustors. More research effort is required to understand the combustion instability characteristics of these burners. The closely-spaced, small-scale flames increases the potential for flame-to-flame interaction with significant implications on the flame response to flow perturbations and the instability driving mechanisms. Transverse-mode instabilities can also exist in such burner configurations which will lead to added complexities.

- Numerical simulations are increasingly being utilised to complement experimental approaches in the development and optimisation of low emissions gas turbine combustors. LES has evolved as a very powerful computational tool for accurately simulating the highly turbulent reacting flows found in practical combustion systems including the effects of flame-acoustic interactions. However, numerical combustion instability studies for pure hydrogen and hydrogenenriched natural gas flames in swirl-stabilised LPM combustors are very limited. LES has the potential to provide deep insights into phenomena which are prohibitively expensive to investigate with experiments. A research area of immediate interest is the simulation of combustion instabilities for hydrogen-enriched flames at the elevated pressures and temperatures obtainable in real-world gas turbines.

Author Contributions: writing—original draft preparation, J.B.; writing—review and editing, All; supervision, S.S., M.T. and R.B. All authors have read and agreed to the published version of the manuscript.

Funding: The authors gratefully acknowledge financial support from Siemens Industrial Turbomachinery Ltd., UKRI Future Leaders Fellowship (MR/T019735/1) and EPSRC (EP/P003036/1) toward this work. This study is also part of HYFLEXPOWER project that has received funding from the European Union's Horizon 2020 Research and Innovation Programme under grant agreement No. 884229.

Institutional Review Board Statement: Not applicable.

Informed Consent Statement: Not applicable. 
Data Availability Statement: No new data were created or analyzed in this study. Data sharing is not applicable to this article.

Conflicts of Interest: The authors declare no conflict of interest.

$\begin{array}{ll}\text { Abbreviations } \\ \phi & \text { Equivalence ratio } \\ \text { CRZ } & \text { Central recirculation zone } \\ \text { DLE } & \text { Dry low emissions } \\ \text { FTF } & \text { Flame transfer function } \\ \text { LBO } & \text { Lean blowout } \\ \text { LES } & \text { Large Eddy Simulation } \\ \text { LPM } & \text { Lean premixed } \\ \text { LSI } & \text { Low swirl injector } \\ \text { ORZ } & \text { Outer recirculation zone } \\ \text { OSL } & \text { Outer shear layer } \\ \text { PIV } & \text { Particle image velocimetry } \\ \text { PLIF } & \text { Planar laser-induced fluorescence } \\ \text { POD } & \text { Proper orthogonal decomposition } \\ \text { RET } & \text { Renewable energy technologies } \\ \text { RI } & \text { Rayleigh index } \\ \text { RMS } & \text { Root mean square }\end{array}$

\section{References}

1. IEA. World Energy Outlook 2019; Report; International Energy Agency: Paris, France, 2019.

2. UN. The Paris Agreement; United Nations: Paris, France, 2015.

3. IRENA. Hydrogen from Renewable Power: Technology Outlook for the Energy Transition; Report; International Renewable Energy Agency (IRENA): Abu Dhabi, UAE, 2018.

4. IEA. The Future of Hydrogen: Seizing Today's Opportunities; Report; International Energy Agency: Paris, France, 2019.

5. Van Nuffel, L.; Dedecca, J.G.; Smit, T.; Rademaekers, K. Sector Coupling: How Can It Be Enhanced in the EU to Foster Grid Stability and Decarbonise? Policy Document PE 626.091; European Parliament: Brussels, Belgium, 2018.

6. Olczak, M.; Piebalgs, A. Sector Coupling: The New EU Climate and Energy Paradigm? Policy Brief; European University Institute: Florence, Italy, 2018.

7. Hydrogen Council. How Hydrogen Empowers the Energy Transition; Report; Hydrogen Council: Brussels, Belgium, 2017.

8. WEC. Hydrogen an Enabler of the Grand Transition-Future Energy Leader Position Paper; Report; Future Energy Leaders, Hydrogen Taskforce: UK, 2018.

9. IEA. Technology Roadmap: Hydrogen and Fuel Cells; Technical Report; International Energy Agency: Paris, France, 2015.

10. Smeets, F.; Vaes, J. Electrolysis Systems for Grid Relieving. In Hydrogen Science and Engineering: Materials, Processes, Systems and Technology; John Wiley \& Sons, Ltd: Weinheim, Germany, 2016; pp. 253-282. [CrossRef]

11. Gahleitner, G. Hydrogen from Renewable Electricity: An International Review of Power-to-Gas Pilot Plants for Stationary Applications. Int. J. Hydrog. Energy 2013, 38, 2039-2061. [CrossRef]

12. Winkler-Goldstein, R.; Rastetter, A. Power to Gas: The Final Breakthrough for the Hydrogen Economy. Green 2013, 3, 69-78. [CrossRef]

13. Jansohn, P. Overview of Gas Turbine Types and Applications. In Modern Gas Turbine Systems; Elsevier: Cambridge, UK, 2013; pp. 21-43. [CrossRef]

14. ETN Global. Hydrogen Gas Turbines: The Path Towards a Zero-Carbon Gas Turbine; Report; European Turbine Network Global: Brussels, Belgium, 2020.

15. IRENA. Renewable Capacity Statistics 2020; Report; International Renewable Energy Agency (IRENA): Abu Dhabi, UAE, 2020.

16. Jansohn, P. (Ed.) Modern Gas Turbine Systems: High Efficiency, Low Emission, Fuel Flexible Power Generation; Woodhead Publishing Limited: Cambridge, UK, 2013.

17. Goldmeer, J. Fuel Flexible Gas Turbines as Enablers for a Low or Reduced Carbon Energy Ecosystem; Technical Report GEA33861; General Electric Company: Vienna, Austria, 2018.

18. EUTurbines. The Gas Turbine Industry Commitments to Drive Europe's Transition to a Decarbonised Energy Mix. Available online: https: / / powertheeu.eu/ (accessed on 29 November 2019).

19. Griebel, P. Gas Turbines and Hydrogen. In Hydrogen Science and Engineering: Materials, Processes, Systems and Technology; John Wiley \& Sons, Ltd.: Weinheim, Germany, 2016; pp. 1011-1032. [CrossRef]

20. Lefebvre, A.H.; Ballal, D.R. Gas Turbine Combustion: Alternative Fuels and Emissions, 3rd ed.; CRC Press: Boca Raton, FL, USA, 2010.

21. Lieuwen, T.C.; Yang, V. (Eds.) Gas Turbine Emissions; Cambridge Aerospace Series; Cambridge University Press: Cambridge, UK, 2013. 
22. Keller, J.J. Thermoacoustic Oscillations in Combustion Chambers of Gas Turbines. AIAA J. 1995, 33, 2280-2287. [CrossRef]

23. Candel, S. Combustion Dynamics and Control: Progress and Challenges. Proc. Combust. Inst. 2002, 29, 1-28. [CrossRef]

24. Lieuwen, T.C.; Yang, V. (Eds.) Combustion Instabilities In Gas Turbine Engines: Operational Experience, Fundamental Mechanisms, and Modeling; Progress in Astronautics and Aeronautics; American Institute of Aeronautics and Astronautics (AIAA): Reston, VA, USA, 2005; Volume 210.

25. Huang, Y.; Yang, V. Dynamics and Stability of Lean-Premixed Swirl-Stabilized Combustion. Prog. Energy Combust. Sci. 2009, 35, 293-364. [CrossRef]

26. Hord, J. Is Hydrogen a Safe Fuel? Int. J. Hydrog. Energy 1978, 3, 157-176. [CrossRef]

27. Taamallah, S.; Vogiatzaki, K.; Alzahrani, F.; Mokheimer, E.; Habib, M.; Ghoniem, A. Fuel Flexibility, Stability and Emissions in Premixed Hydrogen-Rich Gas Turbine Combustion: Technology, Fundamentals, and Numerical Simulations. Appl. Energy 2015, 154, 1020-1047. [CrossRef]

28. McCarty, R.D.; Hord, J.; Roder, H.M. Selected Properties of Hydrogen (Engineering Design Data); US Government Printing Office: Washington, DC, USA, 1981.

29. Goodwin, D.G.; Moffat, H.K.; Speth, R.L. Cantera: An Object-Oriented Software Toolkit for Chemical Kinetics, Thermodynamics, and Transport Processes. 2018. Version 2.4.0. Available online: https://zenodo.org/record/1174508\#.X_UxBBYRVPY (accessed on 30 January 2020).

30. Smith, G.P.; Golden, D.M.; Frenklach, M.; Moriarty, N.; Eiteneer, B.; Goldenberg, M.; Bowman, C.T.; Hanson, R.K.; Song, S.; Gardiner, W.C.; et al. GRI-Mech 3.0. 2000. Available online: http:/ / www.me.berkeley.edu/gri_mech/ (accessed on 30 January 2020).

31. Beér, J.M. Combustion Aerodynamics/J.M. Beér and N.A. Chigier; Fuel and Energy Science Series; Applied Science Publishers Ltd.: Barking, UK, 1972.

32. Lieuwen, T.; McDonell, V.; Santavicca, D.; Sattelmayer, T. Burner Development and Operability Issues Associated with Steady Flowing Syngas Fired Combustors. Combust. Sci. Technol. 2008, 180, 1169-1192. [CrossRef]

33. Benim, A.C.; Syed, K.J. Flashback Mechanisms in Lean Premixed Gas Turbine Combustion; Elsevier: Amsterdam, The Netherlands, 2015.

34. Lieuwen, T.; McDonell, V.; Petersen, E.; Santavicca, D. Fuel Flexibility Influences on Premixed Combustor Blowout, Flashback, Autoignition, and Stability. J. Eng. Gas Turbines Power 2008, 130. [CrossRef]

35. Lieuwen, T.C. Unsteady Combustor Physics; Cambridge University Press: Cambridge, UK, 2012. [CrossRef]

36. Poinsot, T. Prediction and Control of Combustion Instabilities in Real Engines. Proc. Combust. Inst. 2017, 36, 1-28. [CrossRef]

37. Ducruix, S.; Schuller, T.; Durox, D.; Candel, S. Combustion Instability Mechanisms In Premixed Combustors. In Combustion Instabilities in Gas Turbine Engines; Lieuwen, T.C., Yang, V., Eds.; American Institute of Aeronautics and Astronautics (AIAA): Reston, VA, USA, 2005; pp. 179-212. [CrossRef]

38. Dowling, A.P.; Morgans, A.S. Feedback Control of Combustion Oscillations. Annu. Rev. Fluid Mech. 2005, 37, 151-182. [CrossRef]

39. Sewell, J.B.; Sobieski, P.A. Monitoring of Combustion Instabilities: Calpine's Experience. In Combustion Instabilities in Gas Turbine Engines-Operational Experience, Fundamental Mechanisms, and Modelling_Progress in Astronautics and Aeronautics; Lieuwen, T.C., Yang, V., Eds.; American Institute of Aeronautics and Astronautics (AIAA): Reston, VA, USA, 2005; Volume 210, pp. 147-162.

40. Krebs, W.; Bethke, S.; Lepers, J.; Flohr, P.; Prade, B.; Johnson, C.; Sattinger, S. Thermoacoustic Design Tools And Passive Control: Siemens Power Generation Approaches. In Combustion Instabilities in Gas Turbine Engines; Lieuwen, T.C., Yang, V., Eds.; American Institute of Aeronautics and Astronautics (AIAA): Reston, VA, USA, 2005; pp. 89-112. [CrossRef]

41. Zinn, B.T.; Lieuwen, T.C. Combustion Instabilities: Basic Concepts. In Combustion Instabilities in Gas Turbine Engines-Operational Experience, Fundamental Mechanisms, and Modeling_Progress in Astronautics and Aeronautics; Lieuwen, T.C., Yang, V., Eds.; American Institute of Aeronautics and Astronautics (AIAA): Reston, VA, USA, 2005; Volume 210.

42. Candel, S.; Durox, D.; Schuller, T.; Palies, P.; Bourgouin, J.F.; Moeck, J.P. Progress and Challenges in Swirling Flame Dynamics. Comptes Rendus Mécanique 2012, 340, 758-768. [CrossRef]

43. Ducruix, S.; Schuller, T.; Durox, D.; Candel, S. Combustion Dynamics and Instabilities: Elementary Coupling and Driving Mechanisms. J. Propuls. Power 2003, 19, 722-734. [CrossRef]

44. Scarinci, T. Combustion Instability And Its Passive Control: Rolls-Royce Aeroderivative Engine Experience. In Combustion Instabilities in Gas Turbine Engines; Lieuwen, T.C., Yang, V., Eds.; American Institute of Aeronautics and Astronautics: Reston, VA, USA, 2005; pp. 65-88. [CrossRef]

45. Andrews, G. Ultra-Low Nitrogen Oxides (NOx ) Emissions Combustion in Gas Turbine Systems. In Modern Gas Turbine Systems; Elsevier: Cambridge, UK, 2013; pp. 715-790. [CrossRef]

46. Rayleigh. The Explanation of Certain Acoustical Phenomena 1. Nature 1878, 18, 319-321. [CrossRef]

47. Lieuwen, T.; Zinn, B.T. The Role of Equivalence Ratio Oscillations in Driving Combustion Instabilities in Low NOx Gas Turbines. Symp. Int. Combust. 1998, 27, 1809-1816. [CrossRef]

48. Nicoud, F.; Poinsot, T. Thermoacoustic Instabilities: Should the Rayleigh Criterion Be Extended to Include Entropy Changes? Combust. Flame 2005, 142, 153-159. [CrossRef]

49. O'Connor, J.; Acharya, V.; Lieuwen, T. Transverse Combustion Instabilities: Acoustic, Fluid Mechanic, and Flame Processes. Prog. Energy Combust. Sci. 2015, 49, 1-39. [CrossRef]

50. Dowling, A.P.; Stow, S.R. Acoustic Analysis of Gas Turbine Combustors. J. Propuls. Power 2003, 19, 751-764. [CrossRef]

51. Poinsot, T.J.; Trouve, A.C.; Veynante, D.P.; Candel, S.M.; Esposito, E.J. Vortex-Driven Acoustically Coupled Combustion Instabilities. J. Fluid Mech. 1987, 177, 265-292. [CrossRef] 
52. Candel, S.M. Combustion Instabilities Coupled by Pressure Waves and Their Active Control. Symp. Int. Combust. 1992, 24, 1277-1296. [CrossRef]

53. Lieuwen, T.; Torres, H.; Johnson, C.; Zinn, B.T. A Mechanism of Combustion Instability in Lean Premixed Gas Turbine Combustors. J. Eng. Gas Turbines Power 2001, 123, 182-189. [CrossRef]

54. Palies, P.; Durox, D.; Schuller, T.; Candel, S. The Combined Dynamics of Swirler and Turbulent Premixed Swirling Flames. Combust. Flame 2010, 157, 1698-1717. [CrossRef]

55. Morgans, A.S.; Duran, I. Entropy Noise: A Review of Theory, Progress and Challenges. Int. J. Spray Combust. Dyn. 2016, 8, 285-298. [CrossRef]

56. O'Connor, J.; Hemchandra, S.; Lieuwen, T. Combustion Instabilities in Lean Premixed Systems. In Lean Combustion; Elsevier: London, UK, 2016; pp. 231-259. [CrossRef]

57. Venkataraman, K.K.; Preston, L.H.; Simons, D.W.; Lee, B.J.; Lee, J.G.; Santavicca, D.A. Mechanism of Combustion Instability in a Lean Premixed Dump Combustor. J. Propuls. Power 1999, 15, 909-918. [CrossRef]

58. Richards, G.A.; Straub, D.L.; Robey, E.H. Passive Control of Combustion Instabilities in Stationary Gas Turbines. In Combustion Instabilities in Gas Turbine Engines-Operational Experience, Fundamental Mechanisms, and Modeling-Progress in Astronautics and Aeronautics; Lieuwen, T.C., Yang, V., Eds.; American Institute of Aeronautics and Astronautics (AIAA): Reston, VA, USA, 2005; Volume 210, pp. 533-579.

59. McManus, K.R.; Poinsot, T.; Candel, S.M. A Review of Active Control of Combustion Instabilities. Prog. Energy Combust. Sci. 1993, 19, 1-29. [CrossRef]

60. Janus, M.C.; Richards, R.A.; Yip, M.J.; Robey, E.H. Effects of Ambient Conditions and Fuel Composition on Combustion Stability. In Proceedings of the 1997 American Society of Mechanical Engineers (ASME)/International Gas Turbine Institute (IGTI) Turbo Expo Meeting, Orlando, FL, USA, 2-5 June 1997; p. 13.

61. Figura, L.; Lee, J.G.; Quay, B.D.; Santavicca, D.A. The Effects of Fuel Composition on Flame Structure and Combustion Dynamics in a Lean Premixed Combustor; Volume 2: Turbo Expo 2007; ASMEDC: Montreal, QC, Canada, 2007. [CrossRef]

62. Taamallah, S.; LaBry, Z.A.; Shanbhogue, S.J.; Ghoniem, A.F. Thermo-Acoustic Instabilities in Lean Premixed Swirl-Stabilized Combustion and Their Link to Acoustically Coupled and Decoupled Flame Macrostructures. Proc. Combust. Inst. 2015, 35, 3273-3282. [CrossRef]

63. Schefer, R.W.; Wicksall, D.M.; Agrawal, A.K. Combustion of Hydrogen-Enriched Methane in a Lean Premixed Swirl-Stabilized Burner. Proc. Combust. Inst. 2002, 29, 843-851. [CrossRef]

64. Therkelsen, P.L.; Portillo, J.E.; Littlejohn, D.; Martin, S.M.; Cheng, R.K. Self-Induced Unstable Behaviors of CH4 and H2/CH4 Flames in a Model Combustor with a Low-Swirl Injector. Combust. Flame 2013, 160, 307-321. [CrossRef]

65. Zhang, J.; Ratner, A. Experimental Study on the Excitation of Thermoacoustic Instability of Hydrogen-Methane/Air Premixed Flames under Atmospheric and Elevated Pressure Conditions. Int. J. Hydrog. Energy 2019, 44, 21324-21335. [CrossRef]

66. Griebel, P.; Boschek, E.; Jansohn, P. Lean Blowout Limits and NOx Emissions of Turbulent, Lean Premixed, Hydrogen-Enriched Methane/Air Flames at High Pressure. J. Eng. Gas Turbines Power 2007, 129, 404-410. [CrossRef]

67. Emadi, M.; Karkow, D.; Salameh, T.; Gohil, A.; Ratner, A. Flame Structure Changes Resulting from Hydrogen-Enrichment and Pressurization for Low-Swirl Premixed Methane-Air Flames. Int. J. Hydrog. Energy 2012, 37, 10397-10404. [CrossRef]

68. Karlis, E.; Liu, Y.; Hardalupas, Y.; Taylor, A.M.K.P. H2 Enrichment of CH4 Blends in Lean Premixed Gas Turbine Combustion: An Experimental Study on Effects on Flame Shape and Thermoacoustic Oscillation Dynamics. Fuel 2019, 254, 115524. [CrossRef]

69. Lee, M.C.; Yoon, J.; Joo, S.; Kim, J.; Hwang, J.; Yoon, Y. Investigation into the Cause of High Multi-Mode Combustion Instability of $\mathrm{H}_{2} / \mathrm{CO} / \mathrm{CH}_{4}$ Syngas in a Partially Premixed Gas Turbine Model Combustor. Proc. Combust. Inst. 2015, 35, 3263-3271. [CrossRef]

70. Park, J.; Lee, M.C. Combustion Instability Characteristics of $\mathrm{H}_{2} / \mathrm{CO} / \mathrm{CH}_{4}$ Syngases and Synthetic Natural Gases in a PartiallyPremixed Gas Turbine Combustor: Part I-Frequency and Mode Analysis. Int. J. Hydrog. Energy 2016, 41, 7484-7493. [CrossRef]

71. Kim, Y.J.; Yoon, Y.; Lee, M.C. On the Observation of High-Order, Multi-Mode, Thermo-Acoustic Combustion Instability in a Model Gas Turbine Combustor Firing Hydrogen Containing Syngases. Int. J. Hydrog. Energy 2019, 44, 11111-11120. [CrossRef]

72. Lantz, A.; Collin, R.; Aldén, M.; Lindholm, A.; Larfeldt, J.; Lörstad, D. Investigation of Hydrogen Enriched Natural Gas Flames in a SGT-700/800 Burner Using OH PLIF and Chemiluminescence Imaging. J. Eng. Gas Turbines Power 2015, 137. [CrossRef]

73. Moëll, D.; Lörstad, D.; Bai, X.S. LES of Hydrogen Enriched Methane/Air Combustion in the SGT-800 Burner at Real Engine Conditions; Volume 4B: Combustion, Fuels, and Emissions; American Society of Mechanical Engineers: Oslo, Norway, 2018; p. V04BT04A023. [CrossRef]

74. Wicksall, D.M.; Agrawal, A.K. Acoustics Measurements in a Lean Premixed Combustor Operated on Hydrogen/Hydrocarbon Fuel Mixtures. Int. J. Hydrog. Energy 2007, 32, 1103-1112. [CrossRef]

75. Shanbhogue, S.J.; Sanusi, Y.S.; Taamallah, S.; Habib, M.A.; Mokheimer, E.M.A.; Ghoniem, A.F. Flame Macrostructures, Combustion Instability and Extinction Strain Scaling in Swirl-Stabilized Premixed $\mathrm{CH}_{4} / \mathrm{H}_{2}$ Combustion. Combust. Flame 2016, 163, 494-507. [CrossRef]

76. Subash, A.A.; Kim, H.; Moller, S.I.; Richter, M.; Brackmann, C.; Alden, M.; Lantz, A.; Lindholm, A.; Larfeldt, J.; Lorstad, D. Investigation of Fuel and Load Flexibility in a SGT-600/700/800 Burner Under Atmospheric Pressure Conditions Using HighSpeed OH-PLIF and OH Chemiluminescence Imaging. In ASME Turbo Expo 2020: Turbomachinery Technical Conference and Exposition; American Society of Mechanical Engineers: New York, NY, USA, 2020; p. 11. 
77. Kim, K.T.; Lee, J.G.; Lee, H.J.; Quay, B.D.; Santavicca, D.A. Characterization of Forced Flame Response of Swirl-Stabilized Turbulent Lean-Premixed Flames in a Gas Turbine Combustor. J. Eng. Gas Turbines Power 2010, 132. [CrossRef]

78. Moell, D. Modelling of Methane and Hydrogen Enriched Methane Flames in Industrial Gas Turbine Burners. Ph.D. Thesis, Lund University, Lund, Sweden, 2018.

79. Kim, K.T. Forced Response of Swirl Stabilized Flames in Hydrogen Enriched Gas Turbines. Ph.D. Thesis, The Pennsylvania State University, Pennsylvania, PA, USA, 2009.

80. Ge, B.; Ji, Y.; Zhang, Z.; Zang, S.; Tian, Y.; Yu, H.; Chen, M.; Jiao, G.; Zhang, D. Experiment Study on the Combustion Performance of Hydrogen-Enriched Natural Gas in a DLE Burner. Int. J. Hydrog. Energy 2019, 44, 14023-14031. [CrossRef]

81. Wang, M.; Zhong, Y.; Deng, K. Experiment Investigation of the Effects of Hydrogen Content on the Combustion Instability of Methane/Hydrogen Lean Premixed Swirl Flames under Different Acoustic Frequency Ranges. AIP Adv. 2019, 9, 045206. [CrossRef]

82. Cheng, R.K.; Littlejohn, D.; Strakey, P.A.; Sidwell, T. Laboratory Investigations of a Low-Swirl Injector with $\mathrm{H}_{2}$ and $\mathrm{CH}_{4}$ at Gas Turbine Conditions. Proc. Combust. Inst. 2009, 32, 3001-3009. [CrossRef]

83. Davis, D.W.; Therkelsen, P.L.; Littlejohn, D.; Cheng, R.K. Effects of Hydrogen on the Thermo-Acoustics Coupling Mechanisms of Low-Swirl Injector Flames in a Model Gas Turbine Combustor. Proc. Combust. Inst. 2013, 34, 3135-3143. [CrossRef]

84. Tuncer, O.; Acharya, S.; Uhm, J.H. Dynamics, NOx and Flashback Characteristics of Confined Premixed Hydrogen-Enriched Methane Flames. Int. J. Hydrog. Energy 2009, 34, 496-506. [CrossRef]

85. García-Armingol, T.; Ballester, J. Operational Issues in Premixed Combustion of Hydrogen-Enriched and Syngas Fuels. Int. J. Hydrog. Energy 2015, 40, 1229-1243. [CrossRef]

86. Runyon, J.; Marsh, R.; Pugh, D.; Bowen, P.; Giles, A.; Morris, S.; Valera-Medina, A. Experimental Analysis of Confinement and Swirl Effects on Premixed CH4-H2 Flame Behavior in a Pressurized Generic Swirl Burner; Volume 4B: Combustion, Fuels and Emissions; American Society of Mechanical Engineers: Charlotte, NC, USA, 2017; p. V04BT04A044. [CrossRef]

87. Lam, K.K.; Parsania, N. Hydrogen Enriched Combustion Testing of Siemens SGT-400 at High Pressure Conditions; Volume 4B: Combustion, Fuels and Emissions; American Society of Mechanical Engineers: Seoul, Korea, 2016; p. V04BT04A019. [CrossRef]

88. Lam, K.K.; Geipel, P.; Larfeldt, J. Hydrogen Enriched Combustion Testing of Siemens Industrial SGT-400 at Atmospheric Conditions. J. Eng. Gas Turbines Power 2014, 137. [CrossRef]

89. Inoue, K.; Miyamoto, K.; Domen, S.; Tamura, I.; Kawakami, T.; Tanimura, S. Development of Hydrogen and Natural Gas Co-Firing Gas Turbine. Mitsubishi Heavy Ind. Tech. Rev. 2018, 55, 6.

90. Bothien, M.R.; Ciani, A.; Wood, J.P.; Fruechtel, G. Toward Decarbonized Power Generation With Gas Turbines by Using Sequential Combustion for Burning Hydrogen. J. Eng. Gas Turbines Power 2019, 141. [CrossRef]

91. Oztarlik, G.; Selle, L.; Poinsot, T.; Schuller, T. Suppression of Instabilities of Swirled Premixed Flames with Minimal Secondary Hydrogen Injection. Combust. Flame 2020, 214, 266-276. [CrossRef]

92. York, W.D.; Ziminsky, W.S.; Yilmaz, E. Development and Testing of a Low NOx Hydrogen Combustion System for Heavy Duty Gas Turbines; ASME Turbo Expo 2012; American Society of Mechanical Engineers: Copenhagen, Denmark, $2012 ;$ p. 11.

93. Asai, T.; Miura, K.; Matsubara, Y.; Akiyama, Y.; Karishuku, M.; Dodo, S.; Okazaki, T.; Tanimura, S. Development of Gas Turbine Combustors for Fuel Flexibility. In The Future of Gas Turbine Technology; European Turbine Network: Brussels, Belgium, 2016 ; p. 9.

94. Tekin, N.; Ashikaga, M.; Horikawa, A.; Funke, H. Enhancement of Fuel Flexibility of Industrial Gas Turbines by Development of Innovative Hydrogen Combustion Systems. Gas Energy 2018, 2, 18-23.

95. Lee, H.; Hernandez, S.; McDonell, V.; Steinthorsson, E.; Mansour, A.; Hollon, B. Development of Flashback Resistant Low-Emission Micro-Mixing Fuel Injector for 100\% Hydrogen and Syngas Fuels; Volume 2: Combustion, Fuels and Emissions; ASMEDC: Orlando, FL, USA, 2009; pp. 411-419. [CrossRef]

96. Lee, T.; Kim, K.T. Combustion Dynamics of Lean Fully-Premixed Hydrogen-Air Flames in a Mesoscale Multinozzle Array. Combust. Flame 2020, 218, 234-246. [CrossRef]

97. Funke, H.H.W.; Beckmann, N.; Abanteriba, S. An Overview on Dry Low NOx Micromix Combustor Development for HydrogenRich Gas Turbine Applications. Int. J. Hydrog. Energy 2019, 44, 6978-6990. [CrossRef]

98. Funke, H.H.W.; Dickhoff, J.; Keinz, J.; Ayed, A.H.; Parente, A.; Hendrick, P. Experimental and Numerical Study of the Micromix Combustion Principle Applied for Hydrogen and Hydrogen-Rich Syngas as Fuel with Increased Energy Density for Industrial Gas Turbine Applications. Energy Procedia 2014, 61, 1736-1739. [CrossRef]

99. Balachandran, R.; Ayoola, B.O.; Kaminski, C.F.; Dowling, A.P.; Mastorakos, E. Experimental Investigation of the Nonlinear Response of Turbulent Premixed Flames to Imposed Inlet Velocity Oscillations. Combust. Flame 2005, 143, 37-55. [CrossRef]

100. McClure, J.; Abbott, D.; Agarwal, P.; Sun, X.; Babazzi, G.; Sethi, V.; Gauthier, P. Comparison of Hydrogen Micromix Flame Transfer Functions Determined Using RANS and LES; Volume 3: Coal, Biomass, Hydrogen, and Alternative Fuels; Cycle Innovations; Electric Power; Industrial and Cogeneration; Organic Rankine Cycle Power Systems; American Society of Mechanical Engineers: Phoenix, AZ, USA, 2019; p. V003T03A009. [CrossRef]

101. Ćosić, B.; Terhaar, S.; Moeck, J.P.; Paschereit, C.O. Response of a Swirl-Stabilized Flame to Simultaneous Perturbations in Equivalence Ratio and Velocity at High Oscillation Amplitudes. Combust. Flame 2015, 162, 1046-1062. [CrossRef] 
102. Hosseini, S.M.R.; Gardner, C.; Lawn, C. The Non-Linear Thermo-Acoustic Response of a Small Swirl Burner. Combust. Flame 2012, 159, 1909-1920. [CrossRef]

103. Xia, Y.; Laera, D.; Jones, W.P.; Morgans, A.S. Numerical Prediction of the Flame Describing Function and Thermoacoustic Limit Cycle for a Pressurised Gas Turbine Combustor. Combust. Sci. Technol. 2019, 191, 979-1002. [CrossRef] 